\title{
Review Article \\ Commercially Important Medicinal Plants of South Africa: A Review
}

\author{
R. A. Street, ${ }^{1}$ and G. Prinsloo ${ }^{2}$ \\ ${ }^{1}$ Traditional Medicine Laboratory, University of KwaZulu-Natal, Howard College Campus, Durban 4041, South Africa \\ ${ }^{2}$ Department of Agriculture and Animal Health, University of South Africa (UNISA), Florida Campus, Florida 1710, South Africa
}

Correspondence should be addressed to R. A. Street; street@ukzn.ac.za

Received 12 October 2012; Accepted 7 November 2012

Academic Editor: A. Hamid A. Hadi

Copyright (C) 2013 R. A. Street and G. Prinsloo. This is an open access article distributed under the Creative Commons Attribution License, which permits unrestricted use, distribution, and reproduction in any medium, provided the original work is properly cited.

\begin{abstract}
There is a growing interest in natural plant-based remedies as a source for commercial products. Around $80 \%$ of the South African population use traditional medicines to meet their primary health care needs; however, only a few South African medicinal plants have been exploited to their full potential in terms of commercialization. The opportunity for bioprospecting of plant compounds for novel pharmaceuticals remains largely untapped. Certain renowned medicinal plants of international acclaim including buchu and rooibos are currently contributing to local enterprise; however, other exciting opportunities exist for commonly used plants which have not yet reached the international arena. This paper focuses on the key research and development contributions of 10 commercially important medicinal plants of South Africa. Traditional uses, scientific validation, commercialisation developments, as well as both potential opportunities and setbacks are discussed.
\end{abstract}

\section{Introduction}

Medicinal plants have been used for centuries, and numerous cultures still rely on indigenous medicinal plants for their primary health care needs $[1,2]$. South Africa, a country with a strong history of traditional healing, hosts a variety of around 30,000 flowering plant species [3], accounting for almost $10 \%$ of the world's higher plant species [4]. Medicinal plants are now universally recognised as the basis for a number of critical human health, social, and economic support systems and benefits [5]. There has been a major resurgence in interest in traditionally used medicinal plants with a number of international and local initiatives actively exploring the botanical resources of southern Africa with the intention to screen indigenous plants for pharmacologically active compounds $[2,6]$. Studies to determine the chemical profile and composition of medicinal plants reveal the complexity and variety of compounds all contributing to the various uses of plants in treating numerous aliments including lifethreatening diseases such as HIV-AIDS, cancer, and diabetes. There is, however, a need for alternative supply of medicinal plant material as wild plants are under extreme pressure of increased demands for local and export markets. Wiersum et al. [7] reported that the intensive harvesting of wild medicinal plants due to the increasing use has in many places resulted in overexploitation and is a serious threat to biodiversity in the region. The only option for many species is cultivation at a large scale so that the wild species are maintained and become financial viable [8]. This may also contribute to a growing economy and job creation for a developing country such as South Africa by researching and exploiting the chemical treasures contained in the floral kingdom. It is estimated that up to 700,000 tonnes of plant material is consumed annually to the value of about 150 million US dollars [7]. Significant research and development opportunities exist to discover novel and useful biological activities for South African medicinal plants [9]. The aim of this paper is to review 10 prominently used South African medicinal plants. Traditional uses, scientific validation, current commercialisation developments, as well as both potential opportunities and setbacks with regards to future research and development will be discussed. 


\section{Agathosma betulina (Rutaceae)}

2.1. Introduction. Agathosma betulina (Berg.) pillans is a woody shrub, commonly known as Buchu [10]. It is endemic to the Western Cape Cederburg region of South Africa and adapted to dry conditions and can be found on sunny hillsides of rocky-sandstone slopes [11]. The Khoi-San word "Buchu" is used for any fragrant plant that could be dried and powdered and therefore did not refer to a single species, but today, "Buchu" refers to the species A. betulina (round-leaf buchu; "bergboegoe"; short buchu) and Agathosma crenulata (oval-leaf buchu; "anysboegoe"; long-leaf buchu) [12]. Buchu plant material processed into buchu oil, buchu extract, dried buchu leaves, buchu water, and powdered buchu is not only used for medicinal and cosmetic purposes, but also as flavouring agents in the food industry [10]. Buchu is highly sought after globally for its essential oils, especially since it contains high diosphenol and low pulegone content [12].

2.2. Traditional Uses. Buchu is an important plant in the Khoi-San tradition [4] and still enjoys a great reputation as a general health tonic, diuretic, and mild urinary antiseptic [10]. The essential oil is a valuable flavour product and is probably responsible for the antispasmodic, antiseptic, and diuretic activities $[13,14]$. Some medicinal uses of $A$. betulina include treatment as an antispasmodic, antipyretic, liniment, cough remedy, cold and flu remedy, diuretic, treatment of kidney and urinary tract infections, haematuria, prostatitis, cholera, stomach ailments, rheumatism, gout, bruises, calculus, and an antiseptic $[15,16]$. Tinctures of buchu have a great reputation as general health tonics, treatment for stomach aches, use as aromatic bitters, diuretics, and mild urinary antiseptics [4]. The San lubricated their bodies with aromatic plants mixed with fat to keep their skin soft and moist in the desert climate. The lubrication also served as an antibacterial and antifungal protectant, acted as an insect repellent, a deodorant, and to promote the general well-being of the body by uptake of the aromatic substances through the skin [10].

\subsection{Phytochemistry and Biological Activity. The composition} of buchu has been well studied, and numerous compounds have been identified. The compounds identified in A. betulina mostly focused on the volatile fractions of the plant and included limonene, menthone, diosphenol, $l$-pulegone [17] with isomenthone, and diosphenol as the major volatile compounds $[18,19]$ responsible for the distinctive flavour but probably also for antispasmodic, antiseptic, and diuretic activities [12-14, 20]. The commercially important sulphurcontaining compounds are a characteristic of $A$. betulina (cis and trans-8-mercapto-p-methan-3-one), and although these occur in small amounts, they are responsible for the characteristic organoleptic properties of the oil [21]. No alkaloids have been found in A. betulina [12]. Animicrobial activity, antioxidant activity, and anti-inflammatory activity have been demonstrated in A. betulina but showed weak antioxidant activity, with extracts having $\mathrm{IC}_{50}$ values $>100 \mu \mathrm{g} / \mathrm{mL}$ [12]. Extracts were active against all pathogens tested in a study by Moolla et al. [12] with greater activity towards the Gram-positive bacteria than the Gram-negative bacteria.

2.4. Toxicity. The extract of $A$. betulina was investigated by Moolla et al. [12] for toxicity and was found not to be toxic at $\mathrm{IC}_{50}$ values of up to $100 \mu \mathrm{g} / \mathrm{mL}$, but with serial dilution, different degrees of cellular inhibition were displayed, and the samples proved to be toxic in a dose dependant manner.

2.5. Commercialisation and Conservation. Buchu has been wild harvested at least since 1820 and cultivated since the 1970 s or perhaps even earlier [20]. Until 1995, the only reliable source of buchu material was from plants growing in the wild. Diminished habitat, increased commercial demand, destructive wild harvesting practices, and growing genetic vulnerability to natural disasters are all serious threats to sustainable supply of buchu and survival of genetic material in the wild [22]. Recent efforts in crop development have resulted in buchu now being a viable option for small-scale farming [20]. However, cultivation of buchu as a commercial crop is not yet developed, and several research questions need to be addressed to supply the demand of buchu with cultivated material [22]. Incorrect cutting procedures, over harvesting, and poor harvesting regimes inhibit buchu plants from producing seed for its next generation. Frequent fires, invasive alien plants, structural development, and increasing agricultural practices are all contributing to declining populations of buchu in their natural environment [22]. Buchu is a high value crop where fresh plant material currently sells for R35/kg. Approximately 20,000 plants can be planted per hectare, and the oil yield is approximately one percent, depending on the water status of the plant at harvesting. Global production of buchu essential oil falls into the category of 1-50 tonnes and is classified as one of the top 20 in this class [23]. Moolla and Viljoen [22] reported that the oil sells on the international market for about 700 Euros per kilogram, and buchu seed sells for R20 000 per kilogram, and Lubbe and Verpoorte [23] reported the price of buchu at $\$ 56 / \mathrm{kg}$ for cultivated material. These economic figures make cultivation of buchu very attractive and an excellent crop to provide an income for small-scale farmers with small quantities of land available for cultivation. Buchu is harvested by hand, and since no mechanical equipment is used, it can significantly contribute to job creation and sustainable income generation in South Africa [22].

\section{Aloe ferox (Asphodelaceae)}

3.1. Introduction. Aloe ferox (Mill.), commonly known as Cape Aloe or bitter Aloe, is a single-stemmed, robust aloe reaching a height of around $10 \mathrm{~m}$ tall. The broad, succulent leaves reach around $1 \mathrm{~m}$ in length. "Ferox" meaning "ferocious" refers to the thorny sharp red-brownish spines on the leaves [24]. Bright red or orange flowers are produced between May and August, and the rich nectar attracts numerous insects and birds [25]. Although A. ferox has an extensive 
distribution in South Africa, it is largely concentrated along the eastern parts [26].

3.2. Traditional Uses. Aloe ferox is highly regarded for its laxative properties [25]. The leaf is traditionally used for skin and hair treatments [15]. Cut leaves are applied directly to burns, insect bites, sores, and sunburn [25]. Leaf and stem decoctions are used as emetics, whilst leaves and roots are boiled in water and taken for hypertension and stress [27]. Traditional preparations are also used for arthritis, conjunctivitis, toothaches, sinusitis, and stomach pains [25].

3.3. Phytochemistry and Biological Activity. The Cape Aloe leaf can be divided into two main portions: the external green rind and the internal clear pulp. The major components in fresh aloe bitters of the green rind are aloeresin A, aloein, and aloin, representing $70 \%-97 \%$ of total dry weight in a ratio of approximately $4: 3: 2$, respectively [28]. The phytochemistry of $A$. ferox has been comprehensively studied, and numerous classes of compounds have been isolated including chromones, anthraquinones, anthrones, anthrone$\mathrm{C}$-glycosides, and other phenolic compounds (for a detailed review, see Chen et al. [24]). A study on the chemical composition of volatile constituents from the leaves of A. ferox identified 21 compounds, representing more than 99.99\% of the essential oil [29]. The most abundant components of the volatile compounds included 3,6 octatriene (23.86\%), 3-cyclohexane-1-hetanol (7.31\%), bornylene (5.24\%), 1, 3cyclopentadiene (4.07\%), and 5-methyl-3-heptanol (3.92\%). Scientific studies have verified numerous traditional uses such as laxative effects [30] and antioxidant [31], antiinflammatory [32, 33], antimicrobial [34], anthelmintic [35], and anticancer [36] properties. Using the low-dose streptozotocin diabetes rat model, recent studies have shown promise of A. ferox in treating diabetes [37].

3.4. Toxicity. Preparation of A. ferox is generally considered safe; however, adverse effects such as hypersensitivity have been described [24]. It is advised that preparations should be avoided during pregnancy [38].

3.5. Commercialization and Conservation. Aloe ferox was first exported to Europe in 1761 and today is considered South Africa's main wild-harvested commercially traded species [24]. The selection of high-yielding sources, with total aloin levels above $25 \%$, is recommended for commercial cultivation [39]. Apart from its medicinal applications, owing to the gels richness in minerals, amino acids, vitamins, and trace elements, it is extensively used in the cosmetic industry too [40]. The industry yields some 400 tonnes of dried leaf exudate per annum from the leaves of around 10 million plants [41] with the worth to small-scale rural harvesters in the region of R12-15 million per year [42]. Although there is a high harvesting pressure on this species, leaf harvesting can be done sustainably with minimal risk to plant survival [25]. None the less, possible size classes on which harvesting should be discouraged include the small, prereproductive individuals and individuals taller than $2.5 \mathrm{~m}$ which are too tall to be harvested by hand [42]. In South Africa, the A. ferox industry is covered by topical legislative developments in bioprospecting, access, and benefit sharing regulations within the National Environmental Management Biodiversity Act [43]. As the industry expands, the potential of the A. ferox to bring economic gains to underprivileged rural areas has been acknowledged, but success will depend on effective policy governing access to the resource and vigilant sustainability management [43].

\section{Aspalathus linearis (Fabaceae)}

4.1. Introduction. Aspalathus linearis (Burm.f.) Dahlg. produces the well-known herbal tea, called rooibos, also known as the long-life tea in Africa [44], and is endemic to the South African fynbos species [45]. Rooibos tea has become a popular herbal tea with a growing reputation of having important health benefits, including antispasmodic, antioxidant, antiageing, and antieczema activities $[4,10,15,45,46]$. The characteristic sensory quality of rooibos infusions is described as a mixture of honey, woody, and herbal-floral flavours with a slightly sweet taste and a subtle astringent mouthfeel [47]. Other flavours include caramel and a sweetassociated fruity flavour and sometimes off-taints such as grassy, hay-like, and musty/dusty notes and a slightly bitter or sour taste in poor quality tea [47]. Rooibos is exported to the East and Europe [48] and is currently sold in more than 37 countries with Germany, The Netherlands, the United Kingdom, Japan, and the United States of America representing $86 \%$ of the export market in 2010 . The popularity of rooibos can be ascribed to its health-promoting properties, no harmful stimulants, as well as the lower tannin content when compared to black tea (Camellia sinensis) $[10,49]$.

4.2. Traditional Uses. Rooibos is a traditional beverage of the Khoi-descended people of the Cape. The Khoi crudely processed it by cutting, bruising, fermenting, and drying the twigs and leaves [10]. The first person to realise the commercial potential of rooibos as a herbal tea was Benjamin Ginsberg, a merchant of Clanwilliam, who started marketing it in 1904. It was, however, only by 1930 that the agricultural value of rooibos was recognised by a medical practitioner and nature lover, P. Le Fras Nortier of Clanwilliam [45]. African women take rooibos during pregnancy to relieve heartburn and nausea; they take it for its iron content, and they give it to their babies for colic relief and as a milk substitute for infants [44]. Rooibos is gaining acclaim for its vitamin, mineral, and antioxidant content and taste. It has become popular as a health drink because of the absence of caffeine or other stimulants and its properties to relieve digestive troubles and antispasmodic properties [10,44].

4.3. Phytochemistry and Biological Activity. Due to the commercial importance and health benefits ascribed to rooibos, the plant has been significantly studied especially related to its antispasmodic, antioxidant, antiageing, and antieczema activities $[4,10,15,45,46]$. Rooibos is known as a caffeinefree herbal tea, although traces of the alkaloid sparteine have 
been reported [50]. Rooibos contains two unique phenolic compounds, namely, aspalathin [51], a dihydrochalcone Cglucoside, and aspalalinin [52], a cyclic dihydrochalcone. Aspalathin and nothofagin, the major rooibos flavonoids, anti-spasmodic only showed moderate antimutagenic effects. The flavonoids quercetin and isoquercitrin have shown mutagenic and promutagenic activity as well as comutagenic and antimutagenic properties in a study by Snijman et al. [53]. Furthermore, aspalathin and nothofagin and their structural flavonoid analogues displayed moderate antimutagenic properties. Compounds such as luteolin and chrysoeriol exhibit similar activity to those of the green tea flavonoid (-) epigallocatechin gallate (EGCG). Rooibos is well known for its antioxidant activity which also relates to its hepatoprotective properties [46] and immune modulating effect in stimulating antibody production [54]. Antimicrobial effects against several bacteria have been demonstrated in a study by Scheepers et al. [55]. Rooibos consumption has also shown to be relevant to heart disease as it significantly improves the lipid profile as well as redox status by modulating the serum lipid profile significantly by decreasing the triacylglycerol and LDLcholesterol levels and increasing the HDL-cholesterol level [56]. Very little information is available on the structure of the tannins from rooibos tea, but the dimer, procyanidin $\mathrm{B} 3$, the trimer, bisfisetinidol bisfisetinidol- $(4 \beta, 6: 4 \beta, 8)$-catechin, and a pentamer have been identified [57]. Other major phenolic compounds present in rooibos include flavones (orientin, isoorientin, vitexin, isovitexin, luteolin, and chrysoeriol), flavanones (dihydro-orientin, dihydro-isoorientin, and hemiphlorin), and flavonols (quercetin, hyperoside, isoquercitrin, and rutin) [52, 57-60]. Phenolic acids, lignans, flavone diglycosides, (+)-catechin, a phenylpyruvic acid glycoside, the flavonol quercetin-3-O-robinobioside, and the coumarins, esculetin and esculin have also been identified $[52,61-64]$.

4.4. Toxicity. Since rooibos has gained popularity as a health beverage, no toxicological studies have been done. A number of studies have addressed aspects of safety and toxicity of rooibos $[46,49]$. Although some compounds in rooibos have been shown to contain mutagenic properties [53], it is, however, very unlikely that the mutagenic effect of rooibos would be relevant to tea drinkers when considering the quantities consumed [46]. It has also been demonstrated that chronic consumption of aqueous extracts of unfermented and fermented rooibos by rats over a period of 10 weeks did not cause any adverse effects in the liver and kidney [46].

4.5. Commercialisation and Conservation. Rooibos tea is a traditional beverage of the Khoi-descended people of the Clanwilliam region in the Cape and is one of only a few indigenous plants of South Africa that have become an important commercial crop [10]. The first attempts at rooibos cultivation were in the early 1930s, but it was only after World War II that commercial cultivation started in earnest. Cultivation occurs mainly in the Cederberg mountain region but extends to areas as far as Darling and Nieuwoudtville [10]. Seedlings are used to propagate the plants, leading to large phonological, and genetic variation in the cultivated plants [46]. It has also been demonstrated by Koch et al. [47] in the sensory attributes among rooibos samples from different regions. The plants are topped to a height of $30 \mathrm{~cm}$ after 8 months to stimulate branching, but full production is only realised after 3 years [46]. Growing participation of other farmers in rooibos production and increased demand over the years expanded the area under cultivation to 36,000 ha with production mainly concentrated in the Clanwilliam area [10]. Only the so called red type or Rocklands type is cultivated, but there is a renewed interest in harvesting some of the wild types for niche markets and fair trade networks [10]. The red type is divided into the selected, improved Nortier type and the Cederberg type (wild-growing). The latter type has broader and coarser leaves than the Nortier type [65]. Wild rooibos regained prominence as a source of income in recent years. Small-scale producer organisations in the Cederberg (Wupperthal) and Southern Bokkeveld (Heiveld) supply wild-harvested rooibos under organic and fair trade certification to niche markets abroad [66]. Wild rooibos comprises about $2 \%-5 \%$ of the annual production of 40 tons rooibos by the Heiveld Cooperative [67]. Wupperthal's production of wild-harvested rooibos is approximately 10 tons [68]. The market for rooibos showed a steady increase over the years from 5633 tons in 2010 compared to 750 tons in 1993 [69]. By 2010, sales of rooibos have reached more than 5000 tons with an estimated retail sales value of R429 million [46]. Annual production from plantations has reached 20000 tonnes per annum, and export volumes now exceed local consumption [20].

\section{Harpagophytum procumbens (Pedaliaceae)}

5.1. Introduction. Harpagophytum procumbens (DC. ex Meisn.) is a perennial herb native to countries within the southern African continent such as Botswana, Namibia, and South Africa [70]. The weedy plant has grey/green leaves with yellow and violet or uniformly dark tubular flowers [10]. The vernacular name, devils claw, is derived from its fruit which are covered in small claw-like protrusions [70]. Originally, these were considered an irritation to beef farmers as the fruit can cripple an animal if lodged on its feet, but this also encourages seed dispersal [71].

5.2. Traditional Uses. The part used medicinally is the waterstoring secondary tuberous roots which are formed in order to survive the dry seasons encountered in the sub-Saharan regions [70]. The plant is commonly used to treat rheumatism, arthritis, diabetes, gastrointestinal, disturbances, menstrual difficulties, neuralgia, headache, heartburn, and gout $[10,72]$ in the form of infusions, decoctions, tinctures, powders, and extracts [71]. While infusions and decoctions are the most central traditional methods of preparation, the alleged main active principles in the plant are prone to hydrolysis [71].

5.3. Phytochemistry and Biological Activity. The activity of $H$. procumbens has been attributed to iridoid glycosides, mainly harpagoside $(0.5 \%$ to $3 \%)$, with lesser amounts of 
harpagide and procumbide [10]. Though the phytochemistry of this plant has been well researched, there is a scantiness of information on the additive or synergistic effects of the chief compounds [71]. Scientific studies of the biological activity of $H$. procumbens affirm traditional uses including analgesic, antioxidant, antidiabetic, antiepileptic, and antimalarial properties-for an extensive up-to-date review, see Mncwangi et al. [71].

The therapeutic effect appears to be derived only for the whole extract as separate components show little to no advantageous effects [40]. From numerous in vitro and ex vivo studies, it is clear that $H$. procumbens has noteworthy effects on numerous proinflammatory markers [73, 74]; however, the exact mechanism(s) of action responsible for the antiinflammatory/analgesic actions remain elusive [70, 71]. A recent hypothesis is that $H$. procumbens inhibits induction of proinflammatory gene expression, perchance by blocking the AP-1 pathway [75]. The hydrolysed products of the harpagide and harpagoside have significant anti-inflammatory activity when compared to the unhydrolysed compounds [76]. Dosage of $H$. procumbens root extract used in clinical trials in low back pain typically ranges from 2 to $4.5 \mathrm{mg}$ daily corresponding to around 30-100 mg harpogaside [72].

5.4. Toxicity. The clinical trials conducted to date offer support regarding $H$. procumbens as a beneficial treatment for the alleviation of pain and improvement of mobility in a range of musculoskeletal conditions, either as a singular therapy or as an adjunct [70]. However, a systematic review on the safety of Harpagophytum preparations for osteoarthritic and low back pain revealed adverse events (mainly gastrointestinal) during treatment [77]. To date, there are no reports on negative interactions with conventional drugs ordinarily used for rheumatoid arthrosic conditions thereby supporting the utilization of $H$. procumbens as an adjunct therapy for these complaints [70]. Although there are no reports on chronic toxicity, more safety data are urgently needed to assure the safety of Harpagophytum use, particularly long term [77]. In light of possible cardio activity, it is not recommended for long periods of time [72]. Owing to the lack of data regarding the effect of $H$. procumbens during pregnancy and lactation, it should be avoided [72].

5.5. Commercialization and Conservation. Harpagophytum procumbens is traded under the pharmaceutical name of Harpagophyti radix [78]. Harpagophytum spp. products are mostly registered as a herbal medicine in France and Germany or as a food supplement in the United Kingdom, The Netherlands, the United States, and the Far East. In the European Pharmacopoeia, common standards for the composition and preparation of $H$. procumbens substances are described with the aim of quality assurance [78]. The harpagoside content of commercial extracts ranges from $0.8 \%$ to $2.3 \%$ [72]. The total trade for all southern African countries is about 700 tonnes per annum, with the largest portion of the world's supply emanating from Namibia [79]. Main importing nations are European counties, Japan, the USA, and Venezuela [40]. The governments of the main range states (Namibia, Botswana, and South Africa) have developed policies and regulations in an attempt to protect the species and to determine a sustainable harvest [78].

\section{Hypoxis hemerocallidea (Hypoxidaceae)}

6.1. Introduction. Hypoxis hemerocallidea, commonly known as African potato, Ilabatheka, Inkomfe, sterretjie, or starflowers, is a genus of the family Hypoxidaceae [80, 81]. In South Africa, the genus is distributed in five provinces, namely, KwaZulu-Natal, Eastern Cape, Mpumalanga, Limpopo, and Gauteng but is also found in Lesotho, Swaziland, Mozambique, and Zimbabwe [81-83]. Medicinally, the African potato has been used by different cultures for many ailments such as bad dreams, cardiac diseases, impotency, apprehension, barrenness, and intestinal parasites, and today it is even used for cancer, headaches, dizziness, as an immune booster, testicular cancer, prostate hypertrophy, burns, and ulcers [82].

6.2. Traditional Uses. A number of medicinal properties have been assigned to the use of $H$. hemerocallide $a$ and is therefore traded in large numbers at medicinal markets. Hypoxis has been used traditionally for benign protatic hypertrophy and urinary tract infections and as a laxative and vermifuge [10]. The corm of the plant has been used in folk medicine to treat a variety of diseases which include common cold, flu, hypertension, adult-onset diabetes, psoriasis, urinary infections, testicular tumours, prostate hypertrophy, HIV/AIDS and some central nervous system disorders, anticancer, antidiabetic, antimicrobial, antioxidant, and anti-inflammatory treatment. The cultural uses of Hypoxis include charm against lightning, thunder, and storms and also as an emetic for fearful dreams. The decoction of other species of Hypoxis is recorded as being used as a steam bath against venereal diseases such as lice $[10,84-86]$. Other traditional uses include treatment of ailments such as asthma, tuberculosis, urinary tract infection, headache, heart weakness, dizziness, duodenal and gastric ulcers, internal cancer tumours, and some central nervous system ailments, specially epilepsy $[10,38,87]$.

6.3. Phytochemistry and Biological Activity. The uses of this plant can probably be attributed to a few of the medicinal compounds found in the plant of which hypoxoside, sitosterol, and its aglycone derivative rooperol are probably the most well-known compounds [38]. Hypoxoside is the trivial name for (E)-1,5 bis(4'-B-D-glucopyranossyloxy-3' hydroxyphenyl)pent-1-en-4-yne which is a norlignan diglucoside isolated from the rootstock of the family Hypoxidaceae. In addition to hypoxoside and rooperol, the rootstocks are reported to contain $\beta$-sitosterols, sterol, monterpene glycosides, stanols, and stigmastanols [84]. The result of the chemical analysis of $H$. hemerocallidea showed that the species have different classes of secondary metabolites, namely, glycosides, polyphenols, saponnins, steroids, and tannins [88]. The rootstock of $H$. hemerocallidea has yielded three cytokinins, identified as zeatin, zeatin riboside, and zeatin glucoside [38]. The high concentration of phytosterols 
such as $\beta$-sitosterols has proven to be effective against benign prostate hypertrophy [89], and a strong decoction of the rootstocks is also used as purgatives [87]. Rooperol may be obtained by treating hypoxoside with a $\beta$-glucosidase to remove the attached glucose groups. $\beta$-glucosidase is an enzyme found predominantly in the gastrointestinal tract [87]. According to Ojewole [85], the findings of the experimental animal study indicate that $H$. hemerocallidea corm aqueous extract possesses anti-inflammatory and antidiabetic properties in the mammalian laboratories animal models used. The rootstock may be useful in the management of adult onset, noninsulin-dependent, type 2, diabetes mellitus [90].

6.4. Toxicity. It was shown conclusively that Hypoxis extracts (45\% hypoxoside) are not toxic [84]. In a later paper, the possible treatment of certain malignancies and HIV-infection with hypoxoside as a putative, nontoxic prodrug is mentioned [91]. The extracts and its bioactive compound hypoxoside have not exhibited toxicity in several clinical or toxicity studies $[84,91]$.

6.5. Commercialisation and Conservation. H. hemerocallidea is an important plant species in traditional medicine in southern Africa, and the use of the corms is so popular that the species is threatened by overharvesting [92]. H. hemerocallidea was found to be one of the top 10 most frequently sold plant species with approximately $11000 \mathrm{~kg} /$ year sold valued at R322 500 [93]. The importance of this plant in traditional medicine and the potential importance in the pharmaceutical industry necessitate an efficient means of propagating these plants [94]. Apart from traditional plant usage, it is also exported to the East and Europe [95], which contributes to the need for sustainable supply. The plant grows easily and in a wide range of environments but is extremely difficult to propagate in large quantities. A considerable amount of work has already been done on tissue culture and seed germination [94, 96-99] but without resolving a method which can supply the market with the material needed at a reasonable cost.

\section{Merwilla natalensis (Hyacinthaceae)}

7.1. Introduction. Merwilla natalensis (Planch.) Speta, also known as Scilla natalensis planch, Merwilla plumbea (Lindl.) is indigenous to South Africa and is distributed throughout the eastern part of South Africa including Lesotho, KwaZulu-Natal, Free-State, Swaziland, and the Northern Province [100]. Merwilla natalensis is traditionally known as "inguduza" which means "searching the body for the cause of the ailment" [101]. The extracts of the bulb are known for their antibacterial, anthelmintic, anti-inflammatory, and antischistosomal medicinal activity and use as ointment for wounds, scarifications, as a laxative, and as an enema [10]. Merwilla is sought after for its traditional and medicinal properties to such an extent that there is a risk of extinction [102].

7.2. Traditional Uses. Merwilla natalensis is used traditionally by various cultures such as the Zulu, Tswana, Swati, and Sotho speaking people in South Africa. The bulb is used traditionally in Africa amongst others for gastrointestinal ailments, sprains and fractures, tumours (cancerous), menstrual pains, infertility, and to support the process in woman to deliver their babies [103]. Cooked bulbs are eaten together with other food by the southern Sotho ethnic people that believed that it treats "internal tumors" [104]. Tswana ethnic people rub the powdered bulb onto their back joints to improve their power and spirit. It has also been administered to treat internal tumors, lumps, or other cancerous or noncancerous swellings by purgatives or an enema [10,15]. Swati ethnic people use boiled water extracts of the bulbs for the treatment of sprains, boils, fractures, and veld sores [104]. Gynaecologically, extracts of Merwilla assist in delivery and relief of menstrual pains (amenorrhea). A decoction of the bulbs is known to be taken as enemas for the fertility of women and to boost libido and potency of men. The decoctions are usually made by boiling the bulb in milk or water [10, 104]. Although the sap released from the plant can burn the skin of humans, ointment is prepared via the decoction method from fresh bulb scales as well as burnt scales to treat external wounds, boils, abscesses, and fractures. The ashes of the burnt plant are rubbed into cuts and scratches for relief [105].

7.3. Phytochemistry and Biological Activity. Numerous studies support the use of the plant for treatment of the previously mentioned ailments. The bulb extracts have shown antibacterial, antischistosomal, anti-inflammatory, and anthelmintic activity in studies by Sparg et al. [100, 103]. The ethanol extracts showed the best activity against several bacteria [103], and the leaf extracts show anticandidal activity with a MIC of $<1 \mathrm{mg} / \mathrm{mL}$ only in spring and autumn, whereas the bulb extracts have a MIC of $>1 \mathrm{mg} / \mathrm{mL}$ in all seasons [106]. The pharmacological active compounds from the bulbs of Merwilla can act against gastrointestinal ailments such as diarrhoea, intestinal worms, constipation, nausea, and stomach aches [38]. Good activity against nematodes of $M$. natalensis extracts was observed where the ethanolic extract killed $50 \%$ of the nematodes, dichloromethane, and hexane extracts (40\%), and water extracts (30\%) [103]. M. natalensis is considered as a soap plant due to its content of saponins which produce foam once in contact with an aqueous solution. The phytochemical screening of $M$. natalensis bulbs revealed the presence of saponins and bufadienolides within the bulbs [103]. Hyacinthaceae species are known to contain cardiac glycosides being confirmed by a study by Kellermen et al. [107]. Antimony (III) chloride ( $\mathrm{SbCl} 3$ ) reagent was used to identify cardiac glycosides, specifically the bufadienolide type with a high probability of Proscillaridin A to be present in M. natalensis bulbs [103]. Most of the Hyacinthaceae species also contain homoisoflavanones, which possess antibacterial activity [108, 109]. Homoisoflavanones were also detected in M. natalensis by Crouch et al. [110], and this is one of the components that are responsible for the antiinflammatory properties [103]. The dichloromethane and hexane extracts of $M$. natalensis resulted in good inhibition against both COX-1 and COX-2, but the aqueous and ethanolic extracts showed no noteworthy activity [103]. In the 
study by Du Toit et al. [109], homoisoflavonones show good activity against Staphylococcus aureus. The simple structure of homoisoflavanones consists of chromane, chromanone, or chromone together with a benzylidene or benzyl group that is attached to the third position of a 16-carbon skeleton $[109,111]$. Poor antibacterial activity against both Grampositive and Gram-negative bacteria was, however, shown with $M$. natalensis extracts [103]. The storage of the bulb did not have any negative influence on the antibacterial activity of the extracts but actually increased the activity [112]. Sparg et al. [103] confirmed that there are no alkaloids present in M. natalensis. Other chemical compounds that are present in $M$. natalensis are five types of nortriterpenoids, one bisnortriterpenoids, and one trisnorterpenoid. Ethanolic extracts had the highest inhibitory effect against nematodes in the anthelmintic assays, and the aqueous extracts of both dry and fresh bulbs showed extremely good activity against Schistosoma haematobium [103].

7.4. Toxicity. With the powerful components that are present in the plant, it can be used as a medicinal plant, but precaution must be taken as it can be toxic. Since cytotoxicity was found, it was suggested that care should be taken when used internally [103]. The toxic cardiac glycoside transvaalin was showed to be the same compound as scillaren A which is found in similar species related to M. natalensis [48] but should still be demonstrated in M. natalensis [10]. No genotoxic effects were found, however, in a study by Elgorashi et al. [113], using the Ames and VITOTOX tests. Genotoxicity was, however, found by Fennell et al. [114], using the micronucleus test where structural and chromosome aberrations were observed. It was also found by Sparg et al. [103] that M. natalansis is extremely toxic to VK cells with morphological changes, cell death, and severe cytotoxicity observed at all concentrations tested.

7.5. Commercialisation and Conservation. Merwilla natalensis is classified as a vulnerable species and therefore included in the red data list [115]. For the reason that $M$. natalensis bulbs are in high demand to support the use of medicinal and traditional use, M. natalensisis is recommended for cultivation [116]. In order to protect the plant from extinction, the supply of Merwilla plants need to be higher than the demand. Slow-growing bulbous and tuberous plants, which are frequently used in traditional Zulu medicine, represent another group of plants that are particularly threatened by overexploitation and recognized by the healers as becoming scarce [117]. Again, the main problem is the destructive harvesting of the underground parts of these plants or even the plant as a whole [118]. The bulbs of Merwilla take 15 years to get to its most preferable size [101]. Merwilla natalensis is one of the cheapest plants per kilogram (R 6.50/kg) [117], and in 2006, 2.1 million bulbs of Merwilla were sold in and around Johannesburg and Durban to the value of R3.87 million [101]. It is extremely easy to cultivate since the plant produces numerous seeds which can be easily germinated with a high survival of the seedlings. Seed propagation is therefore preferred as the most effective method for cultivation [119]. Care should be taken in ensuring quality of cultivated material as reduction in some biological activity was found when cultivated under irrigation [114].

\section{Pelargonium sidoides (Geraniaceae)}

8.1. Introduction. The taxonomic classification of Pelargonium species is noted with some difficulty hence the numerous revisions in the past. Nonetheless, the genus Pelargonium is highly esteemed by traditional healers for its therapeutic and palliative effects in the treatment of gastrointestinal disorders [120]. Pelargonium sidoides DC. is native to the coastline regions of South Africa and Lesotho [2]. The small perennial herb has long-stalked leaves which are slightly aromatic, heart-shaped, and velvety. The characteristic dark, reddish-purple tubular flowers are present throughout most of the year but occur most frequently from late spring to summer $[2,121]$. In the early 20th century, Charles Henry Stevens was treated in South Africa by a traditional health practitioner who claimed that he cured his tuberculosis with a natural remedy containing P. sidoides. "Umckaloabo" is the name used by Stevens for his tuberculosis medicine, a name that still persists today. The term "Umckaloabo" may actually be an origination of Stevens, based on South African languages, intended to create an enigmatic image for his remedy to increase its marketability. In the first half of the 20th century, a product made from the root was used in Europe to treat tuberculosis [2]. A summary of the fascinating history of the commercial development of "Umckaloabo" in Europe is presented in Brendler and van Wyk [122].

8.2. Traditional Uses. Although a modern aqueous-ethanolic formulation of P. sidoides extracts (EPs 7630) is an efficacious treatment for disorders of the respiratory tract, the traditional uses mainly involve disorders of the gastrointestinal tract $[120,122]$. The fleshy, bright red rhizomes or tubers of $P$. sidoides are used predominantly to treat diarrhoea and dysentery $[15,122]$. In fact tannin-containing plant remedies are traditionally used to treat diarrhea [122]. Kalwerbossie is a local name used for $P$. sidoides because the plants were traditionally used as a remedy for worms in calves (kalwers) [122]. In the eastern Cape, the crushed roots of P. sidoides are mixed with water after which a teaspoon is given orally to infants with upset stomachs [123].

8.3. Phytochemistry and Biological Activity. According to a comprehensive review of the chemical constituents of $P$. sidoides by Kolodziej [124], the extreme involvedness of the metabolites in P. sidoides is reflected by the occurrence of abundant coumarins, coumarin glycosides, coumarin sulphates, flavonoids, proanthocyanidins, phenolic acids, and phenylpropanoid derivatives. The antibacterial and antiviral properties are accredited to gallic acids and other phenolic compounds, while the immunomodulatory activity is alleged to be due to a combination of phenolic compounds and the numerous coumarins [122]. A systematic review and meta-analysis regarding the use of $P$. sidoides to treat acute bronchitis concluded that there is encouraging evidence from 
currently available data indicating that $P$. sidoides is effective compared to placebo for patients with acute bronchitis [125]. Despite the commercial interest in P. sidoides, few studies have been conducted to document the phytochemical variation for natural populations [126].

8.4. Toxicity. A total of 18 clinical trials have thus far been conducted, several of which were randomised, doubleblind, and placebo-controlled. Overall safety and a very low incidence of side effects were confirmed [122]. Recent reports $(n=15)$ of primarily assumed hepatotoxicity in connection with the use of $P$. sidoides have been interpreted by the Drug Commission of the German Medical Association (DCGMA). After analysis of these reports, Teschke et al. [127] concluded that there is little if any conclusive evidence and that assessments of these cases do not fulfil essential criteria required to propose the existence of $P$. sidoides hepatotoxicity.

8.5. Commercialization and Conservation. Since the 1990s, a prodelphinidin-rich ethanolic extract, made from the tuberous roots of $P$. sidoides called EPs 7630 (Umckaloabo), licensed to treat respiratory tract infections such as acute bronchitis, has become one of the most successful phytomedicines in the world $[20,128]$. The annual sales in Germany alone exceed $€ 80$ million [20]. A preparation of $P$. sidoides mother tincture is marketed in Ukraine, Russia, and Latvia as Umkalor [2]. Proprietary extracts of $P$. sidoides and their preparations as well as the use thereof are currently protected by seven patents worldwide [2]. Most of the plant material used is still being wild harvested by locals from rural communities in South Africa [129]. Official annual harvest data are not available but are estimated to be between $9,00 \mathrm{~kg}$ and $45,000 \mathrm{~kg}$ [2].

\section{Sclerocarya birrea (Anacardiaceae)}

9.1. Introduction. The name Sclerocarya is derived from the Greek word for hard (skleros) and nut (karyon) [2]. Sclerocarya birrea (A.Rich.) Hochst. subsp. caffra, also known as marula, is widely distributed in northern and western parts of Africa, but only the subspecies caffra is found in southern Africa [10]. Owing to its ability to provide two fundamental needs, namely, food and medicine [130], S. birrea is also referred to as the "tree of life" and is one of the most important trees of the southern African region. It is regarded sacred and protected in communal lands under the local chiefs [2]. Marula is a medium-sized deciduous tree of up to 15 meters in height with the male and female flowers habitually appearing on separate trees. The flowers are small, with red sepals and yellow petals [4]. The fruit, which averages around 20-30 g, is yellow when ripe with a white juicy flesh which clings to a hard stone, inside which are 2-3 seeds [2]. It is considered a drought-tolerant medicinal plant species with potential role in land rehabilitation [131].

9.2. Traditional Uses. Various cultures have utilized different plants of $S$. birrea to manage, control, and/or treat numerous ailments. For example, the bark is used to treat dysentery and diarrhea, rheumatism, and insect bites $[2,15]$ and is believed to be a cure for malaria and proctitis [38]. Essence from the leaves is said to provide relief from abscesses, burns and spider bites, whilst the marula oil is used as a balm to treat ear, nose, and throat conditions [2]. The fruit is used for the destruction of ticks [38]. It is interesting to note that leaves are predominantly used in Namibia where it is believed that the medicinal powers of male trees are greater than those of female trees, whereas the marula bark is more important in South Africa [132].

9.3. Phytochemistry and Biological Activity. The fruits of $S$. birrea are rich in ascorbic acid (168 mg/100 g) [133], and the fruit juice contains sesquiterpene hydrocarbons including caryophyllene, $\alpha$-humulene, and copaene [134]. The fruit kernels contain high amounts of oil $(47 \mathrm{mg} / \mathrm{g}$ dry weight mostly due to oleic acid), protein (36.4\% dry weight), and are a good source of minerals $(\mathrm{Cu}, \mathrm{Mg}$, and $\mathrm{Zn}$ at 24.8, 4210 , and $62.4 \mu \mathrm{g} / \mathrm{g}$ dry weight, resp.) [135]. The oil-rich seeds contain oleic, myristic, and stearic fatty acids and different types of amino acids, with a predominance of glutamic acid and arginine. However, when compared with the World Health Organization protein standard, the seeds contain low proportions of several of the essential amino acids, including leucine, lysine, the phenylalanine/tyrosine pair, and threonine [134]. The bark yields 5.5\%-20.5\% tannin and $10.7 \%$ tannin matter [15]. Numerous in vitro and in vivo studies to confirm biological activity include antidiarrheal, anti-inflammatory, antimalarial, antimicrobial, antiplasmodial, antihypertensive, anticonvulsant, antinociceptive, and antioxidant investigations which have been undertaken to verify traditional use of various plant parts [136-139]. It is suggested that S. Birrea stem bark extracts exert reno- and cardio-protective effects in diabetes mellitus [140]. Bark and leaf ethanolic extracts tested for antimicrobial activity ranged from 0.15 to $3 \mathrm{mg} / \mathrm{mL}$ [136]. Based on minimum inhibitory concentration values, inner bark extracts tended to be the most potent followed by outer bark and then the leaf extracts. Marula stem bark is shown to have exhibited high in vitro and in vivo (mouse model) antimalarial properties [138].

9.4. Toxicity. In vitro and in vivo toxicity studies of various $S$. birrea plant parts have shown conflicting results $[141,142]$. A recent study on the effect of marula juice on albino rats has indicated that the marula juice may have an effect on liver and kidney functions at high dose [143].

9.5. Commercialization and Conservation. All parts of the marula tree can be used, making it one of the most valuable cultural and economic resources in southern Africa [144]. Its potential to generate cash income makes it a principally significant tree species which deserves more consideration in terms of utilization [130]. Marula has acquired significant commercial prominence since its fruits and other products entered local, regional, and international trade in the Southern Africa region; however, there are no reports on 
commercialization of the species in East and Central regions of Africa [135]. In 1985, it was reported that 600 tonnes of juice was produced in South Africa alone [145]. Numerous small enterprises in southern Africa produce Marula jam and jellies [145].

The only product which has realised its full export potential is Amarula Cream. A marula cosmetic extract has been patented by Phytotrade in conjunction with Aldivia, a French company [2]. There is a threat that commercialisation of $S$. birrea will lead to the increased "privatisation" and the marginalization of certain groups from due benefits, or that commercialization will draw resources into trade and away from important subsistence uses [146].

\section{Siphonochilus aethiopicus (Zingiberaceae)}

10.1. Introduction. Siphonochilus aethiopicus (Schweinf.) B. L. Burtt is commonly known as wild ginger or African ginger, with a restricted distribution in South Africa where it is only found in Mpumalanga and the Northern Province and has become extinct in KwaZulu-Natal [10]. It also grows in Zimbabwe, Malawi, and Zambia. Wild ginger is regarded as one of the most important medicinal plant species of South Africa [15]. The rhizomes and roots are used for a variety of ailments, including coughs, colds, asthma, headache, candida, malaria, and influenza, but also for hysteria, pain and several other traditional and cultural practices [10, 15, $38,147]$. Wild ginger is the main commercial species that is relatively known as a result of its popularity in traditional medicine and concerns about its conservation status [147].

10.2. Traditional Uses. Wild ginger is one of the most important medicinal species with a long history of traditional use and one of the most popular of all traditional medicinal plants of southern Africa [147]. Wild ginger in South Africa is regarded as one of the most traded species and consequently has become overexploited and is now rare or extinct in the wild [148]. The increasing demand for this plant is leading to serious overharvesting from the wild and presents an opportunity for potentially profitable cultivation. The rhizomes are chewed fresh to treat asthma, hysteria, cold, flu, coughs, pain relief, dysmenorrhea, influenza, hysteria, as well as to treat malaria and also chewed by women during menstruation [10]. The highly aromatic roots have been reported to be used by Zulu people as a protection against lightning [10].

10.3. Phytochemistry and Biological Activity. Since S. aethiopicus is one of the most important medicinal plants in South Africa, much attention has been paid to the chemistry and biological activity of the plant. Studies revealed the healing properties of the rhizomes and roots for a variety of ailments including coughs, colds, asthma, headache, candida, and malaria [4, 15]. More recently, the application of the sesquiterpenoid siphonochilone and extracts containing siphonochilone from $S$. aethiopicus have been patented for application of the anti-inflammatory activities in formulations treating asthma and allergic conditions [9]. Two new furanoterpenoid derivatives, namely, 4aaH-3,5a,8ab-trimethyl-4,4a,9-tetrahydro-naphtho[2,3-b]-furan-8-one and 2hydroxy-4aaH-3,5a,8ab-trimethyl-4,4a,9-tetrahydronaphtho[2,3-b]-furan-8-one, were also isolated from S. aethiopicus $[10,149,150]$. It is widely used in the treatment of pain and inflammation [114]. The composition of the essential oil was described by Viljoen et al. [150].

10.4. Toxicity. Siphonochilus aethiopicus was found to cause DNA damage as detected in the comet assay which raised some concern for the use of the plant [151]. It was expressed by Fennell et al. [114] that prescription of this plant for the treatment of ailments should be treated with caution, and rigorous toxicological and clinical studies are necessary before they are widely prescribed for use in traditional medicine as they can cause damage to the DNA and might therefore have long-term effects on the body.

10.5. Commercialisation and Conservation. In 1993, African ginger was identified as one of the South African species with commercial production potential as it is in high demand and short supply [8]. It is often quoted as being locally extinct in some parts of South Africa as a result of overexploitation $[117,148]$. As more plants are harvested and overexploited for financial gain, the need for genetic conservation of medicinal plants is emphasized as more of the wild populations are facing extinction [152]. In a study by Mander [153], it was estimated that 1.9 tonnes of African ginger totalling a number of 52,000 plants is traded annually in KwaZulu-Natal. The current situation necessitates an alternative supply of medicinal plant material to meet demand. The only option for many species is cultivation at a large scale so that the wild species are maintained and become financial viable [8]. S. aethiopicus is easy to propagate and cultivate and successfully cultivated in the warm parts of South Africa [147]. Vegetative propagation is the preferred method as this is very efficient and also the fact that the seeds develop and mature underground and therefore are difficult to find and use for propagation [154]. Micropropagation has been established although not widely used and still not incorporated on large scale for production of wild ginger $[4,25]$. Cultivation of wild ginger should be a financially viable operation in South Africa since there is always a demand, and the income generated justifies the effort. Street traders obtain around R140/kg while shops and healers obtain a price of up to R450/kg [153].

\section{Sutherlandia frutescens (Fabaceae)}

11.1. Introduction. Sutherlandia frutescens (L.) R.Br. belongs to the family Fabaceae commonly known as the legume, pea, or bean family. With the genus being restricted to southern Africa [10], this soft-wooded shrub with reedy stems is found in Botswana, Namibia, and South Africa [25]. The large red flowers, around $3 \mathrm{~cm}$ long, are followed shortly by bladderlike fruits [25]. Sutherlandia frutescens is commonly known as the cancer bush because of the reported use by Khoi-San and Cape Dutch people against internal cancers since 1895 $[155,156]$. However, because of its adaptability, S. frutescens 
has several other vernacular names referring to its ethnomedicinal significance. These include "petola" (Setswana) which means "it changes," implying that the plant changes the course of many illnesses towards a positive outcome and "lerumo-lamadi" (Northern Sesotho) meaning "the spear for the blood," indicating that Sutherlandia is a powerful bloodpurifier and all-purpose tonic [157]. Sutherlandia along with $H$. hemerocallidea are the two main African medicinal plants used for treatment of HIV/AIDS and are endorsed by the South African Ministry of Health for HIV management [87].

11.2. Traditional Uses. Sutherlandia frutescens has a lengthy history of medicinal use in southern Africa. Mainly the leaves are used, but all above ground parts are often included [10]. It has been used in the traditional medicine systems of different cultural groups for a wide diversity of ailments, including stomach ailments, backache, diabetes, stress, fever, and wounds [40, 155]. It is used for internal cancers, but despite numerous claims and anecdotes, there is no scientific evidence to confirm this [10]. The dried leaves and other preparations are used as a general tonic [25].

11.3. Phytochemistry and Biological Activity. The chief constituents of $S$. frutescens alleged to be active include L-canavanine, GABA, and D-pinitol. L-canavanine is a nonprotein amino acid which is the L-2-amino-4guanidinooxy structural analogue of L-arginine [87]. GABA and methionine are two amino acids which are highly prone to degradation through hydrolysis; thus, during production this needs to be taken into account [157]. A study by Mncwangi and Viljoen [157] investigating S. frutescens samples collected from different natural populations $(n=87)$ and from a commercial plantation $(n=60)$ revealed tremendous variation in the yields of the different compounds both within and between populations. For example, L-canavanine ranged from 0.14 to $13.58 \mathrm{mg} / \mathrm{g}$. Amino acids collectively constituted between $10 \%$ and $15 \%$ (w/w) of dried S. frutescens. Proline, L-asparagine, and alanine were the most abundant amino acids and collectively represent almost $60 \%$ of total amino acid content; however, not all samples contained all the amino acids. The content of L-canavanine, arginine, GABA, and D-pinitol in seeds, field leaves, and in vitro leaves of $S$. frutescens was quantified by Shaik et al. [158]. The results revealed that the secondary metabolites significantly differed depending on the source. In vitro leaves had higher quantities of all compounds, except for D-pinitol, and the study highlighted the use of in vitro biology for the extraction of $S$. frutescens compounds.

11.4. Toxicity. The long history of traditional use, with no reports of any serious side effects, suggests that Sutherlandia can be considered as being generally safe [155]. The South African Ministry of Health has concluded that this product is safe based on primate safety studies [87]. Recent preclinical studies indicate that concomitant administration of Sutherlandia with prescription drugs (CYP3A4 substrates) could possibly lead to therapeutic failure and clinically relevant drug-herb interactions [159].
11.5. Commercialization and Conservation. In recent years, there has been a marked increase in both scientific and commercial interests in Sutherlandia [155]. The first small-scale cultivation and commercialisation of Sutherlandia started in the Cape Province more than 20 years ago [156]. The first branded products were tablets made from powdered leaves of a selected chemotype named SU1 type, the protypes and products of which have been marketed by Phyto Nova (Pty) Ltd since 2000 [20]. Phyto Nova now pursues large-scale cultivation of this medicinal plant [156]. Although it is not officially sanctioned by regulatory agencies in Europe and US, Sutherlandia is distributed worldwide through internet sources which claim it to be an immunity booster [159].

\section{Conclusion}

South Africa is home to thousands of plant species, each an industry for unique and useful chemical compounds. However, more pragmatic information on medicinal plants would enhance their value in agricultural landscapes by helping farmers improve their livelihoods and ensure environmental sustainability [130]. While it is anticipated that commercialization of certain medicinal plant species will bring financial remunerations to communities, this should not impair the subsistence sector, or sustainability of the resource itself [160]. A drawback of using nonrenewable parts such as bark as a source for the medicinal trade is that removal of bark can lead to the death of the plant. If bark can be traded for a high price, valuable plant populations may be collected to extinction in nature [136]. Traditional medicine has been used for treating diseases over centuries, and scientific studies have revealed that many of them are potentially toxic. The use of more polar solvents could be the reason for plant extracts being less toxic as the toxic compounds will be only extracted in more apolar solvents [115]. Drug-drug interactions are well-known phenomena, and the risks have long been realised. For example, interactions involving the concurrent use of sildenafil, a drug used for erectile dysfunction with nitrates and nitrites, can produce profound hypotension leading to decreased coronary perfusion and myocardial infarction. This potentially fatal drug interaction also led to the withdrawal of several sildenafilcontaining herbal medications from the market [161]. The use of herbs may mimic, magnify, or oppose the effect of drugs and should therefore be used with care, and proper consultation and information should be provided by health care practitioners when mixing herbs and pharmaceutical drugs as interaction with most drugs is not known. Some examples of already identified herb-drug interactions include bleeding when warfarin is combined with ginkgo (Ginkgo biloba), mild serotonin syndrome in patients who mix St John's wort (Hypericum perforatum) with serotonin-reuptake inhibitors, and potentiation of oral and topical corticosteroids by liquorice (Glycyrrhiza glabra) and soluble fibres (including guar gum and psyllium) which can decrease the absorption of drugs. An example of South African herb-drug interactions is the use of devil's claw with the use of warfarin resulting in puprura [162]. In addition, $H$. hemerocallidea and 
S. frutescens showed a negative interaction with antiretroviral medication, thus patients may be at risk from treatment failure, viral resistance, or drug toxicity [163].

Intellectual property rights (IPRs) can both positively and negatively impact the interests of primary producers. In order to appreciate benefits from the use of IPRs, communities need substantial financial and technical support [146]. Bioprospecting and regulation thereof has been heavily debated in the past years to minimize exploitation of South African resources without benefit and recognition for knowledge holders. This regulation has been observed by the scientific community as another hurdle in promoting and developing bioactives [164]. A more contemporary avenue for bioactives is the use of plants as vehicles to make recombinant proteins and other molecules for use as therapeutics. However, this is not well explored in Africa probably because few research laboratories are equipped to do this work [6].

The paper addressed just a few applications of the chemical components of the identified plants and the use as food, beverages, various medicinal uses, cosmetic industry, flavor, and fragrance industry to name a few. Some well-known plants and applications such as rooibos, marula, and buchu oil are already contributing to local communities' upliftment by creating enterprises both from wild harvesting and by cultivation of material. Others such as wild ginger, cancer bush, and the African potato still have potential to become international pharmaceutical and herbal products, and the full potential has not yet been exploited.

\section{Conflict of Interests}

The authors declare that they have no conflict of interests.

\section{Acknowledgments}

The South African Medical Research Council, National Research Foundation (South Africa), the University of South Africa, and the University of KwaZulu-Natal are thanked for their financial assistance.

\section{References}

[1] C. Veilleux and S. R. King, An Introduction to Ethnobotany, 1996, http://www.accessexcellence.org/.

[2] A. Gurib-Fakim, T. Brendler, L. D. Philips, and J. N. Eloff, Green Gold Success Stories Using Southern African Medicinal Plant Species, AAMPS Publishing, 2010.

[3] C. A. M. Louw, T. J. C. Regnier, and L. Korsten, "Medicinal bulbous plants of South Africa and their traditional relevance in the control of infectious diseases," Journal of Ethnopharmacology, vol. 82, no. 2-3, pp. 147-154, 2002.

[4] B. E. Van wyk and N. Gericke, People's Plants. A Guide to Useful Plants of Southern Africa, Briza Publications, 2000.

[5] C. Geldenhuys and D. Mitchell, "Sustainable harvesting technologies," in Commercialising Medicinal Plants-a Southern African Guide, N. Diederichs, Ed., pp. 21-40, Sun Press, Stellenbosch, South Africa, 2006.

[6] E. P. Rybicki, R. Chikwamba, M. Koch, J. I. Rhodes, and J. H. Groenewald, "Plant-made therapeutics: an emerging platform in South Africa," Biotechnology Advances, vol. 30, no. 2, pp. 449-459, 2012.

[7] K. F. Wiersum, A. P. Dold, M. Husselman, and M. Cocks, "Cultivation of medicinal plants as a tool for biodiversity conservation and poverty alleviation in the Amatola region, South Africa," in Medicinal and Aromatic Plants, R. J. Bogers, L. E. Craker, and D. Lange, Eds., pp. 43-57, Springer, 2006.

[8] A. B. Cunningham, "African medicinal plants: setting priorities at the interface between conservation and primary health care," in People and Plants Working Paper, Unesco, 1993.

[9] N. Gericke, "Muthi to medicine," South African Journal of Botany, vol. 77, no. 4, pp. 850-856, 2011.

[10] B. van Wyk, B. van Oudsthoorn, and N. Gericke, Medicinal Plants of South Africa, Briza publications, 1997.

[11] P. Golblatt and J. C. Manning, Cape Plants: a Conspectus of the Cape Flora of South Africa, National Botanical Institute of South Africa, Pretoria, South Africa, 2000.

[12] A. Moolla, S. F. Van Vuuren, R. L. Van Zyl, and A. M. Viljoen, "Biological activity and toxicity profile of 17 Agathosma (Rutaceae) species," South African Journal of Botany, vol. 73, no. 4, pp. 588-592, 2007.

[13] M. Wichtl and N. G. Bisset, Herbal Drugs and Phytopharmaceuticals, CRC Press, Boca Raton, Fla, USA, 2000.

[14] M. Lis-Balchin, S. Hart, and E. Simpson, "Buchu (Agathosma betulina and $A$. crenulata, Rutaceae) essential oils: their pharmacological action on guinea-pig ileum and antimicrobial activity on microorganisms," Journal of Pharmacy and Pharmacology, vol. 53, no. 4, pp. 579-582, 2001.

[15] J. M. Watt and M. G. Breyer-Brandwijk, The Medicinal and Poisonous Plants of Southern and Eastern Africa, Churchill Livingstone, London, UK, 1962.

[16] D. Simpson, "Buchu-South Africa's amazing herbal remedy," Scottish Medical Journal, vol. 43, no. 6, pp. 189-191, 1998.

[17] A. A. J. Fluck, W. M. Mitchell, and H. M. Perry, "Comparison of buchu leaf oil," Journal of the Science and Food Agriculture, vol. 12, pp. 290-292, 1961.

[18] R. Kaiser, D. Lamparsky, and P. Schudel, "Analysis of buchu leaf oil," Journal of Agricultural and Food Chemistry, vol. 23, no. 5, pp. 943-950, 1975.

[19] M. A. Posthumus, T. A. Van Beek, N. F. Collins, and E. H. Graven, "Chemical composition of the essential oils of Agathosma betulina, A. crenulata and an A. betulina x crenulata hybrid (Buchu)," Journal of Essential Oil Research, vol. 8, no. 3, pp. 223-228, 1996.

[20] B. E. Van Wyk, "The potential of South African plants in the development of new medicinal products," South African Journal of Botany, vol. 77, no. 4, pp. 812-829, 2011.

[21] M. Sandasi, G. P. P. Kamatou, M. Baranska, and A. M. Viljoen, "Application of vibrational spectroscopy in the quality assessment of Buchu oil obtained from two commercially important Agathosma species (Rutaceae)," South African Journal of Botany, vol. 76, no. 4, pp. 692-700, 2010.

[22] A. Moolla and A. M. Viljoen, "Buchu'-Agathosma betulina and Agathosma crenulata (Rutaceae): a review," Journal of Ethnopharmacology, vol. 119, no. 3, pp. 413-419, 2008.

[23] A. Lubbe and R. Verpoorte, "Cultivation of medicinal and aromatic plants for specialty industrial materials," Industrial Crops and Products, vol. 34, no. 1, pp. 785-801, 2011.

[24] W. Chen, B. van Wyk, I. Vermaak, and A. Viljoen, "Cape Aloes-A review of the phytochemistry, pharmacology and commercialisation of Aloe ferox," Phytochemistry Letters, vol. 2, pp. 1-12, 2012. 
[25] N. Crouch, R. Symmonds, W. Spring, and N. Diederichs, "Facts sheets for growing popular medicinal plant species," in Commercialising Medicinal Plants-A Southern African Guide, N. Diederichs, Ed., pp. 97-142, Sun Press, Stellenbosch, South Africa, 2006.

[26] B. van Wyk and G. Smith, Guide to the Aloes of South Africa, Briza Publications, 1996.

[27] J. Pujol, Naturaafrica-The Herbalist Handbook, Jean Pujol natural healers foundation, Durban, South African, 1990.

[28] B. van Wyk, B. van Oudsthoorn, and N. Gericke, Medicinal Plants of South African, 2009.

[29] M. L. Magwa, M. Gundidza, R. M. Coopoosamy, and B. Mayekiso, "Chemical composition of volatile constituents from the leaves of Aloe ferox," African Journal of Biotechnology, vol. 5, no. 18, pp. 1652-1654, 2006.

[30] O. A. Wintola, T. O. Sunmonu, and A. J. Afolayan, "The effect of Aloe ferox Mill. In the treatment of loperamide-induced constipation in Wistar rats," BMC Gastroenterology, vol. 10, article 95, 2010.

[31] D. T. Loots, F. H. Van Der Westhuizen, and L. Botes, “Aloe ferox leaf gel phytochemical content, antioxidant capacity, and possible health benefits," Journal of Agricultural and Food Chemistry, vol. 55, no. 17, pp. 6891-6896, 2007.

[32] M. Mwale and P. J. Masika, "Analgesic and anti-inflammatory activities of Aloe ferox Mill. aqueous extract," African Journal of Pharmacy and Pharmacology, vol. 4, no. 6, pp. 291-297, 2010.

[33] O. A. Fawole, S. O. Amoo, A. R. Ndhlala, M. E. Light, J. F. Finnie, and J. Van Staden, "Anti-inflammatory, anticholinesterase, antioxidant and phytochemical properties of medicinal plants used for pain-related ailments in South Africa," Journal of Ethnopharmacology, vol. 127, no. 2, pp. 235-241, 2010.

[34] L. Kambizi, N. Sultana, and A. J. Afolayan, "Bioactive compounds isolated from Aloe ferox: a plant traditionally used for the treatment of sexually transmitted infections in the Eastern Cape, South Africa," Pharmaceutical Biology, vol. 42, no. 8, pp. 636-639, 2005.

[35] V. Maphosa, P. J. Masika, E. S. Bizimenyera, and J. N. Eloff, "Invitro anthelminthic activity of crude aqueous extracts of Aloe ferox, Leonotis leonurus and Elephantorrhiza elephantina against Haemonchus contortus," Tropical Animal Health and Production, vol. 42, no. 2, pp. 301-307, 2010.

[36] S. Kametani, A. Kojima-Yuasa, H. Kikuzaki, D. O. Kennedy, M. Honzawa, and I. Matsui-Yuasa, "Chemical constituents of cape Aloe and their synergistic growth-inhibiting effect on ehrlich ascites tumor cells," Bioscience, Biotechnology and Biochemistry, vol. 71, no. 5, pp. 1220-1229, 2007.

[37] D. T. Loots, M. Pieters, M. S. Islam, and L. Botes, "Antidiabetic effects of Aloe ferox and Aloe greatheadii var. Davyana leaf gel extracts in a low-dose streptozotocin diabetes rat model," South African Journal of Science, vol. 107, no. 7-8, 2011.

[38] A. Hutchings, A. H. Scott, G. Lewis, and A. Cunningham, Zulu Medicinal Plants-An Inventory, University of Natal Press Pietermaritzburg, Pietermaritzburg, South Africa, 1996.

[39] B. E. Van Wijk, M. C. B. R. Van Oudtshoorn, and G. F. Smith, "Geographical variation in the major compounds of Aloe ferox leaf exudate," Planta Medica, vol. 61, no. 3, pp. 250-253, 1995.

[40] S. E. Drewes, M. Horn, and F. Khan, "The chemistry and pharmacology of medicinal plants," in Commercialising Medicinal Plants-A Southern African Guide, N. Diederichs, Ed., pp. 87-96, Sun Press, Stellenbosch, South Africa, 2006.
[41] D. J. Newton and H. Vaughan, South Africa's Aloe ferox Plant Parts and Derivatives Industry, TRAFFIC East/Southern Africa, Johannesburg, South Africa, 1996.

[42] C. M. Shackleton and J. Gambiza, "Growth of Aloe ferox Mill. at selected sites in the Makana region of the Eastern Cape," South African Journal of Botany, vol. 73, no. 2, pp. 266-269, 2007.

[43] O. M. Grace, "Current perspectives on the economic botany of the genus Aloe L., (Xanthorrhoeaceae)," South African Journal of Botany, vol. 77, no. 4, pp. 980-987, 2011.

[44] J. Gruenwald, "Novel botanical ingredients for beverages," Clinics in Dermatology, vol. 27, no. 2, pp. 210-216, 2009.

[45] E. Joubert and D. de Beer, "Rooibos (Aspalathus linearis) beyond the farm gate: from herbal tea to potential phytopharmaceutical," South African Journal of Botany, vol. 77, no. 4, pp. 869-886, 2011.

[46] E. Joubert, W. C. A. Gelderblom, A. Louw, and D. de Beer, "South African herbal teas: Aspalathus linearis, Cyclopia spp. and Athrixia phylicoides-a review," Journal of Ethnopharmacology, vol. 119, no. 3, pp. 376-412, 2008.

[47] I. S. Koch, M. Muller, E. Joubert, M. van der Rijst, and T. Næs, "Sensory characterization of rooibos tea and the development of a rooibos sensory wheel and lexicon," Food Research International, vol. 46, no. 1, pp. 217-228, 2012.

[48] D. A. Mulholland and S. E. Drewes, "Global phytochemistry: indigenous medicinal chemistry on track in southern Africa," Phytochemistry, vol. 65, no. 7, pp. 769-782, 2004.

[49] K. L. J. Blommaert and J. Steenkamp, “Tannin and possible caffeine content of rooibos tea, Aspalathus (Subgen. Nortiera) linearis (Burm. Fil) R. Dahlgr [Afrikaans]," Agroplantae, vol. 10, p. $49,1978$.

[50] B.-E. Van Wyk and G. H. Verdoorn, "Alkaloids of the genera Aspalathus, Rafnia and Wiborgia (Fabaceae-Crotalarieae)," South African Journal of Botany, vol. 55, pp. 520-522, 1989.

[51] B. H. Koeppen and D. G. Roux, "Aspalathin: a novel Cglycosylflavonoid from Aspalathus linearis," Tetrahedron Letters, vol. 6, no. 39, pp. 3497-3503, 1965.

[52] N. Shimamura, T. Miyase, K. Umehara, T. Warashina, and S. Fujii, "Phytoestrogens from Aspalathus linearis," Biological and Pharmaceutical Bulletin, vol. 29, no. 6, pp. 1271-1274, 2006.

[53] P. W. Snijman, S. Swanevelder, E. Joubert, I. R. Green, and W. C. A. Gelderblom, "The antimutagenic activity of the major flavonoids of rooibos (Aspalathus linearis): some dose-response effects on mutagen activation-flavonoid interactions," Mutation Research-Genetic Toxicology and Environmental Mutagenesis, vol. 631, no. 2, pp. 111-123, 2007.

[54] K. Kunishiro, A. Tai, and I. Yamamoto, "Effects of Rooibos tea extract on antigen-specific antibody production and cytokine generation in vitro and in vivo," Bioscience, Biotechnology and Biochemistry, vol. 65, no. 10, pp. 2137-2145, 2001.

[55] S. Scheepers, Anti-microbial activity of rooibos tea (Aspalathus linearis) on food spoilage organisms and potential pathogens, Stellenbosch University, 2001.

[56] J. L. Marnewick, F. Rautenbach, I. Venter et al., "Effects of rooibos (Aspalathus linearis) on oxidative stress and biochemical parameters in adults at risk for cardiovascular disease," Journal of Ethnopharmacology, vol. 133, no. 1, pp. 46-52, 2011.

[57] D. Ferreira, C. Marais, J. A. Steenkamp, and E. Joubert, "Rooibos tea as a likely health food supplements," in Proceedings in Recent Development of Technologies on Fundamental Foods for Health, 1995. 
[58] B. H. Koeppen, J. B. Smit, and D. G. Roux, "The flavone Cglycosides and flavonol $O$-glycosides of Aspalathus acuminatus (rooibos tea)," The Biochemical Journal, vol. 83, pp. 507-511, 1962.

[59] C. Marais, W. J. Van Rensburg, D. Ferreira, and J. A. Steenkamp, "(S)- and (R)-eriodictyol-6-C- $\beta$-D-glucopyranoside, novel keys to the fermentation of rooibos (Aspalathus linearis)," Phytochemistry, vol. 55, no. 1, pp. 43-49, 2000.

[60] C. Rabe, J. A. Steenkamp, E. Joubert, J. F. W. Burger, and D. Ferreira, "Phenolic metabolites from rooibos tea (Aspalathus linearis)," Phytochemistry, vol. 35, no. 6, pp. 1559-1565, 1994.

[61] R. Beltrán-Debón, A. Rull, F. Rodríguez-Sanabria et al., "Continuous administration of polyphenols from aqueous rooibos (Aspalathus linearis) extract ameliorates dietaryinduced metabolic disturbances in hyperlipidemic mice," Phytomedicine, vol. 18, no. 5, pp. 414-424, 2011.

[62] T. Breiter, C. Laue, G. Kressel, S. Gröll, U. H. Engelhardt, and A. Hahn, "Bioavailability and antioxidant potential of rooibos flavonoids in humans following the consumption of different rooibos formulations," Food Chemistry, vol. 128, no. 2, pp. 338-347, 2011.

[63] N. Krafczyk and M. A. Glomb, "Characterization of phenolic compounds in rooibos tea," Journal of Agricultural and Food Chemistry, vol. 56, no. 9, pp. 3368-3376, 2008.

[64] C. Marais, J. A. Steenkamp, and D. Ferreira, "The occurrence of phenylpyruvic acid in woody plants: biosynthetic significance," Tetrahedron Letters, vol. 37, no. 32, pp. 5763-5764, 1996.

[65] J. F. Morton, "Rooibos tea, Aspalathus linearis, a caffeineless, low-tannin beverage," Economic Botany, vol. 37, pp. 164-173, 1983.

[66] E. Nel, T. Binns, and D. Bek, "'Alternative foods' and community-based development: rooibos tea production in South Africa's West Coast Mountains," Applied Geography, vol. 27, no. 2, pp. 112-129, 2007.

[67] S. Patrickson, R. Malgas, and N. Oettlé, "Environmental threat or conservation opportunity?” Veld \& Flora, vol. 94, pp. 8-11, 2008.

[68] T. Binns, D. Bek, E. Nel, and B. Ellison, "Sidestepping the mainstream: fairtrade rooibos tea production in Wupperthal, South Africa," in Alternative Food Geographies, D. Maye, L. Holloway, and M. Kneafsey, Eds., pp. 331-349, Elsevier, Amsterdam, The Netherlands, 2007.

[69] Anon, "Stock situation [Afrikaans]," Die Rooibos, vol. 2, p. 4, 1994.

[70] L. Grant, D. E. McBean, L. Fyfe, and A. M. Warnock, "A review of the biological and potential therapeutic actions of Harpagophytum procumbens," Phytotherapy Research, vol. 21, no. 3, pp. 199-209, 2007.

[71] N. Mncwangi, W. Chen, I. Vermaak, A. M. Viljoen, and N. Gericke, "Devil's claw-a review of the ethnobotany, phytochemistry and biological activity of Harpagophytum procumbens," Journal of Ethnopharmacology, vol. 143, no. 3, pp. 755-771, 2012.

[72] J. Barnes, "Devil's claw (Harpagophytum procumbens). Also known as "grapple plant" or "wood spider"', Journal of Primary Health Care, vol. 1, no. 3, pp. 238-239, 2009.

[73] V. Gyurkovska, K. Alipieva, A. Maciuk et al., "Antiinflammatory activity of Devil's claw in vitro systems and their active constituents," Food Chemistry, vol. 125, no. 1, pp. 171-178, 2011.

[74] J. Qi, N. Li, J. H. Zhou, B. Y. Yu, and S. X. Qiu, "Isolation and anti-inflammatory activity evaluation of triterpenoids and a monoterpenoid glycoside from Harpagophytum procumbens," Planta Medica, vol. 76, no. 16, pp. 1892-1896, 2010.

[75] B. L. Fiebich, E. Muñoz, T. Rose, G. Weiss, and G. P. McGregor, "Molecular targets of the antiinflammatory Harpagophytum procumbens (Devil's claw): inhibition of TNF $\alpha$ and COX-2 gene expression by preventing activation of AP-1," Phytotherapy Research, vol. 26, no. 6, pp. 806-811, 2012.

[76] L. Zhang, L. Feng, Q. Jia et al., "Effects of $\beta$-glucosidase hydrolyzed products of harpagide and harpagoside on cyclooxygenase-2 (COX-2) in vitro," Bioorganic and Medicinal Chemistry, vol. 19, no. 16, pp. 4882-4886, 2011.

[77] J. Vlachojannis, B. D. Roufogalis, S. Chrubasik, and J. Chrubasik, "Systematic review on the safety of Harpagophytum preparations for osteoarthritic and low back pain," Phytotherapy Research, vol. 22, no. 2, pp. 149-152, 2008.

[78] K. M. Stewart and D. Cole, “The commercial harvest of devil's claw (Harpagophytum spp.) in southern Africa: the devil's in the details," Journal of Ethnopharmacology, vol. 100, no. 3, pp. 225-236, 2005.

[79] D. Raimondo and J. Donaldson, "The trade, management and biological status of Harpagophytum spp. in southern African range states. and L. T. N. A report submitted to the twelfth meeting of the CITES Plants Committee," in A report submitted to the twelfth meeting of the CITES Plants Committee, The trade, management and biological status of Harpagophytum spp. in southern African range states, Leiden, The Netherlands, May 2002.

[80] S. E. Drewes, A. J. Hall, R. A. Learmonth, and U. J. Upfold, "Isolation of hypoxoside from Hypoxis rooperi and synthesis of (E)-1,5-bis(3',4'-dimethoxyphenyl)pent-4-en-1-yne," Phytochemistry, vol. 23, no. 6, pp. 1313-1316, 1984.

[81] Y. Singh, "Hypoxis: Yellow stars of horticulture, folk remedies and conventional medicine," Veld and Flora, vol. 85, pp. 123-125, 1999.

[82] S. E. Drewes, E. Elliot, F. Khan, J. T. B. Dhlamini, and M. S. S. Gcumisa, "Hypoxis hemerocallidea-Not merely a cure for benign prostate hyperplasia," Journal of Ethnopharmacology, vol. 119, no. 3, pp. 593-598, 2008.

[83] Y. Singh, "Hypoxis (Hypoxidaceae) in southern Africa: taxonomic notes," South African Journal of Botany, vol. 73, no. 3, pp. 360-365, 2007.

[84] O. Laporta, L. Pérez-Fons, R. Mallavia, N. Caturla, and V. Micol, "Isolation, characterization and antioxidant capacity assessment of the bioactive compounds derived from Hypoxis rooperi corm extract (African potato)," Food Chemistry, vol. 101, no. 4, pp. 1425-1437, 2007.

[85] J. A. O. Ojewole, "Antinociceptive, anti-inflammatory and antidiabetic properties of Hypoxis hemerocallidea Fisch. \& C.A. Mey. (Hypoxidaceae) corm ['African Potato'] aqueous extract in mice and rats," Journal of Ethnopharmacology, vol. 103, no. 1, pp. 126-134, 2006.

[86] V. Steenkamp, M. C. Gouws, M. Gulumian, E. E. Elgorashi, and J. Van Staden, "Studies on antibacterial, anti-inflammatory and antioxidant activity of herbal remedies used in the treatment of benign prostatic hyperplasia and prostatitis," Journal of Ethnopharmacology, vol. 103, no. 1, pp. 71-75, 2006.

[87] E. Mills, C. Cooper, D. Seely, and I. Kanfer, "African herbal medicines in the treatment of HIV: hypoxis and Sutherlandia. An overview of evidence and pharmacology," Nutrition Journal, vol. 4, no. 19, pp. 1-8, 2005. 
[88] O. O. G. Oluwule, N. A. Sukati, P. S. Dlamini, and F. G. Sibandze, "Some Swazi phytomedicines and their constituents," African Journal of Biotechnology, vol. 6, no. 3, pp. 267-272, 2007.

[89] V. Steenkamp, "Phytomedicines for the prostate," Fitoterapia, vol. 74, no. 6, pp. 545-552, 2003.

[90] C. T. Musabayane, K. Xozwa, and J. A. O. Ojewole, "Effects of Hypoxis hemerocallidea (Fisch. \& C.A. Mey.) [Hypoxidaceae] corm (african potato) aqueous extract on renal electrolyte and fluid handling in the rat," Renal Failure, vol. 27, no. 6, pp. 763-770, 2005.

[91] C. F. Albrecht, P. B. Kruger, B. J. Smit et al., "The pharmacokinetic behaviour of hypoxoside taken orally by patients with lung cancer in a phase I trial," South African Medical Journal, vol. 85, no. 9, pp. 861-865, 1995.

[92] D. R. Katerere and J. N. Eloff, "Anti-bacterial and anti-oxidant activity of Hypoxis hemerocallidea (Hypoxidaceae): can leaves be substituted for corms as a conservation strategy?" South African Journal of Botany, vol. 74, no. 4, pp. 613-616, 2008.

[93] A. P. Dold and M. L. Cocks, "The trade in medicinal plants in the Eastern Cape Province, South Africa," South African Journal of Science, vol. 98, no. 11-12, pp. 589-597, 2002.

[94] R. D. Hammerton and J. Van Staden, "Seed germination of Hypoxis hemerocallidea," South African Journal of Botany, vol. 54, no. 3, pp. 277-280, 1988.

[95] D. A. Mulholland and S. E. Drewes, "Global phytochemistry: indigenous medicinal chemistry on track in southern Africa," Phytochemistry, vol. 65, no. 7, pp. 769-782, 2004.

[96] Y. M. Page and J. Van Staden, "In vitro propagation of Hypoxis rooperi," Plant Cell, Tissue and Organ Culture, vol. 3, no. 4, pp. 359-362, 1984.

[97] Y. M. Page and J. Van Staden, "In vitro propagation of Hypoxis rooperi from flower buds," South African Journal of Botany, vol. 52, no. 2, pp. 261-264, 1986.

[98] R. D. Hammerton, M. T. Smith, and J. Van Staden, "Factors influencing seed variability and germination in Hypoxis hemerocallidea," Seed Science and Technology, vol. 17, no. 3, pp. 613-624, 1989.

[99] Y. M. Page and J. Van Staden, "Hypoxoside production in tissue cultures of Hypoxis rooperi," Plant Cell, Tissue and Organ Culture, vol. 9, no. 2, pp. 131-136, 1987.

[100] S. G. Sparg, A. K. Jäger, and J. Van Staden, "The effect of cultivation and plant age on the pharmacological activity of Merwilla natalensis bulbs," South African Journal of Botany, vol. 71, no. 2, pp. 191-196, 2005.

[101] V. L. Williams, D. Raimondo, and A. B. Cunningham, "Trade, bulb age and impacts on Merwilla plumbea," South African Journal of Botany, vol. 73, no. 2, pp. 321-322, 2007.

[102] S. G. Sparg, A. K. Jäger, M. L. Magwa, and J. Van Staden, "Cultivating the medicinal plant Merwilla natalensis as a crop. A small-scale farming approach," Outlook on Agriculture, vol. 34, no. 2, pp. 116-120, 2005.

[103] S. G. Sparg, J. Van Staden, and A. K. Jäger, "Pharmacological and phytochemical screening of two Hyacinthaceae species: Scilla natalensis and Ledebouria ovatifolia," Journal of Ethnopharmacology, vol. 80, no. 1, pp. 95-101, 2002.

[104] N. Moodley, D. A. Mulholland, and N. R. Crouch, "Eucosteroltype nortriterpenoids from Merwilla natalensis," Journal of Natural Products, vol. 67, no. 5, pp. 918-920, 2004.

[105] A. Notten, Merwilla plumbea (Lindl.) Speta, 2001, http://www. plantzafrica.com.
[106] B. Ncube, J. F. Finnie, and J. Van Staden, "Seasonal variation in antimicrobial and phytochemical properties of frequently used medicinal bulbous plants from South Africa," South African Journal of Botany, vol. 77, no. 2, pp. 387-396, 2011.

[107] T. S. Kellermen, J. A. W. Coetzer, and T. W. Naude, Plant Poisonings and Mycotoxicoses of Livestock in South Africa, Oxford University Press, Cape Town, South Africa, 1988.

[108] K. Du Toit, E. E. Elgorashi, S. F. Malan et al., "Antiinflammatory activity and QSAR studies of compounds isolated from Hyacinthaceae species and Tachiadenus longiflorus Griseb. (Gentianaceae)," Bioorganic and Medicinal Chemistry, vol. 13, no. 7, pp. 2561-2568, 2005.

[109] K. Du Toit, E. E. Elgorashi, S. F. Malan, D. A. Mulholland, S. E. Drewes, and J. Van Staden, "Antibacterial activity and QSAR of homoisoflavanones isolated from six Hyacinthaceae species," South African Journal of Botany, vol. 73, no. 2, pp. 236-241, 2007.

[110] N. R. Crouch, V. Bangani, and D. A. Mulholland, "Homoisoflavanones from three South African Scilla species," Phytochemistry, vol. 51, no. 7, pp. 943-946, 1999.

[111] B. S. Kirkiacharian, M. Gomis, H. G. Tongo, J. Mahuteau, and J. D. Brion, Organic Magnetic Resonance, John Wiley \& sons, 1984.

[112] G. I. Stafford, A. K. Jäger, and J. Van Staden, "Effect of storage on the chemical composition and biological activity of several popular South African medicinal plants," Journal of Ethnopharmacology, vol. 97, no. 1, pp. 107-115, 2005.

[113] E. E. Elgorashi, J. L. S. Taylor, A. Maes, J. Van Staden, N. De Kimpe, and L. Verschaeve, "Screening of medicinal plants used in South African traditional medicine for genotoxic effects," Toxicology Letters, vol. 143, no. 2, pp. 195-207, 2003.

[114] C. W. Fennell, K. L. Lindsey, L. J. McGaw et al., "Assessing African medicinal plants for efficacy and safety: pharmacological screening and toxicology," Journal of Ethnopharmacology, vol. 94, no. 2-3, pp. 205-217, 2004.

[115] B. G. Ndawonde, A. M. Zobolo, E. T. Dlamini, and S. J. Siebert, "A survey of plants sold by traders at Zululand muthi markets, with a view to selecting popular plant species for propagation in communal gardens," African Journal of Range and Forage Science, vol. 24, no. 2, pp. 103-107, 2007.

[116] R. A. Street, M. G. Kulkarni, W. A. Stirk et al., "Effect of cadmium uptake and accumulation on growth and antibacterial activity of Merwilla plumbea-an extensively used medicinal plant in South Africa," South African Journal of Botany, vol. 75, no. 3, pp. 611-616, 2009.

[117] A. B. Cunningham, An Investigation of the Herbal Medicinal Trade in Natal/KwaZulu, Institute of Natural Resources, 1988.

[118] S. Zschocke, T. Rabe, J. L. S. Taylor, A. K. Jäger, and J. Van Staden, "Plant part substitution-a way to conserve endangered medicinal plants?" Journal of Ethnopharmacology, vol. 71, no. 12, pp. 281-292, 2000.

[119] S. G. Sparg, M. G. Kulkarni, and J. Van Staden, "Germination and seedling establishment strategies for Merwilla natalensis, a South African medicinal plant in high demand," South African Journal of Science, vol. 101, no. 3-4, pp. 205-208, 2005.

[120] H. Kolodziej, "Antimicrobial, antiviral and immunomodulatory activity studies of Pelargonium sidoides (EPs 7630) in the context of health promotion," Pharmaceuticals, vol. 4, pp. 1295-1314, 2011.

[121] E. Lawrence, Pelargonium Sidoides DC, 2001, http://www. plantzafrica.com/plantnop/pelargsidoid.htm. 
[122] T. Brendler and B. E. van Wyk, "A historical, scientific and commercial perspective on the medicinal use of Pelargonium sidoides (Geraniaceae)," Journal of Ethnopharmacology, vol. 119, no. 3, pp. 420-433, 2008.

[123] B. Matsiliza and N. P. Barker, "A preliminary survey of plants used in traditional medicine in the Grahamstown area," South African Journal of Botany, vol. 67, no. 2, pp. 177-182, 2001.

[124] H. Kolodziej, "Fascinating metabolic pools of Pelargonium sidoides and Pelargonium reniforme, traditional and phytomedicinal sources of the herbal medicine Umckaloabo," Phytomedicine, vol. 14, no. 1, pp. 9-17, 2007.

[125] T. B. Agbabiaka, R. Guo, and E. Ernst, "Pelargonium sidoides for acute bronchitis: a systematic review and meta-analysis," Phytomedicine, vol. 15, no. 5, pp. 378-385, 2008.

[126] J. E. Maree and A. M. Viljoen, "Phytochemical distinction between Pelargonium sidoides and Pelargonium reniforme-a quality control perspective," South African Journal of Botany, vol. 82, no. 0, pp. 83-91, 2012.

[127] R. Teschke, C. Frenzel, J. Schulze, and A. Eickhoff, "Spontaneous reports of primarily suspected herbal hepatotoxicity by Pelargonium sidoides: was causality adequately ascertained?" Regulatory Toxicology and Pharmacology, vol. 63, no. 1, pp. 1-9, 2012.

[128] L. L. Theisen and C. P. Muller, "EPs 7630 (Umckaloabo), an extract from Pelargonium sidoides roots, exerts anti-influenza virus activity in vitro and in vivo," Antiviral Research, vol. 94, no. 2, pp. 147-156, 2012.

[129] F. B. Lewu, P. O. Adebola, and A. J. Afolayan, "Commercial harvesting of Pelargonium sidoides in the Eastern Cape, South Africa: striking a balance between resource conservation and rural livelihoods," Journal of Arid Environments, vol. 70, no. 2, pp. 380-388, 2007.

[130] G. N. Gouwakinnou, A. M. Lykke, A. E. Assogbadjo, and B. Sinsin, "Local knowledge, pattern and diversity of use of Sclerocarya birrea," Journal of Ethnobiology and Ethnomedicine, vol. 7, article 8, 2011.

[131] J. D. H. Lambert, P. A. Ryden, and E. E. Esikuri, Capitalizing on the Bio-Economic Value of Multi-Purpose Medicinal Plants for the Rehabilitation of Drylands in Sub-Saharan Africa, 2005.

[132] S. Shackleton, S. Den Adel, T. McHardy, and C. Shackleton, Use of Marula Products for Domestic and Commercial Purposes: Synthesis of Key Findings from Three Sites in Southern Africa, G.D.f.I. Development, 2002.

[133] A. M. Viljoen, G. P. P. Kamatou, and K. H. C. Başer, "Headspace volatiles of marula (Sclerocarya birrea subsp. caffra)," South African Journal of Botany, vol. 74, no. 2, pp. 325-326, 2008.

[134] A. A. Mariod and S. I. Abdelwahab, "Sclerocarya birrea (Marula), an African tree of nutritional and medicinal uses: a review," Food Reviews International, vol. 28, no. 4, pp. 375-388, 2012.

[135] B. A. Jama, A. M. Mohamed, J. Mulatya, and A. N. Njui, "Comparing the "Big Five": a framework for the sustainable management of indigenous fruit trees in the drylands of East and Central Africa," Ecological Indicators, vol. 8, no. 2, pp. 170-179, 2008.

[136] J. N. Eloff, "Antibacterial activity of Marula (Sclerocarya birrea (A. rich.) Hochst. subsp. caffra (Sond.) Kokwaro) (Anacardiaceae) bark and leaves," Journal of Ethnopharmacology, vol. 76, no. 3, pp. 305-308, 2001.

[137] J. A. O. Ojewole, T. Mawoza, W. D. H. Chiwororo, and P. M. O. Owira, "Sclerocarya birrea (A. Rich) Hochst. ["Marula"]
(Anacardiaceae): a review of its phytochemistry, pharmacology and toxicology and its ethnomedicinal uses," Phytotherapy Research, vol. 24, no. 5, pp. 633-639, 2010.

[138] J. W. Gathirwa, G. M. Rukunga, E. N. M. Njagi et al., "The in vitro anti-plasmodial and in vivo anti-malarial efficacy of combinations of some medicinal plants used traditionally for treatment of malaria by the Meru community in Kenya," Journal of Ethnopharmacology, vol. 115, no. 2, pp. 223-231, 2008.

[139] M. Moyo, A. R. Ndhlala, J. F. Finnie, and J. Van Staden, "Phenolic composition, antioxidant and acetylcholinesterase inhibitory activities of Sclerocarya birrea and Harpephyllum caffrum (Anacardiaceae) extracts," Food Chemistry, vol. 123, no. 1, pp. 69-76, 2010.

[140] M. Gondwe, D. R. Kamadyaapa, M. Tufts, A. A. Chuturgoon, and C. T. Musabayane, "Sclerocarya birrea [(A. Rich.) Hochst.] [Anacardiaceae] stem-bark ethanolic extract (SBE) modulates blood glucose, glomerular filtration rate (GFR) and mean arterial blood pressure (MAP) of STZ-induced diabetic rats," Phytomedicine, vol. 15, no. 9, pp. 699-709, 2008.

[141] L. Verschaeve and J. Van Staden, "Mutagenic and antimutagenic properties of extracts from South African traditional medicinal plants," Journal of Ethnopharmacology, vol. 119, no. 3, pp. 575-587, 2008.

[142] M. van de Venter, S. Roux, L. C. Bungu et al., "Antidiabetic screening and scoring of 11 plants traditionally used in South Africa," Journal of Ethnopharmacology, vol. 119, no. 1, pp. 81-86, 2008.

[143] L. G. Hassan, S. M. Dangoggo, S. W. Hassan, S. Muhammad, and K. J. Umar, "Serum biochemical response of rats fed with Sclerocarya birrea juice extracts," African Journal of Food Science, vol. 5, no. 4, pp. 208-212, 2011.

[144] N. C. Mokgolodi, Y. F. Ding, M. P. Setshogo, C. Ma, and Y. J. Liu, "The importance of an indigenous tree to southern African communities with specific relevance to its domestication and commercialization: a case of the marula tree," Forestry Studies in China, vol. 13, no. 1, pp. 36-44, 2011.

[145] R. R. B. Leakey, "Potential for novel food products from agroforestry trees: a review," Food Chemistry, vol. 66, no. 1, pp. $1-14,1999$.

[146] R. P. Wynberg, S. A. Laird, S. Shackleton et al., "Marula policy brief: marula commercialisation for sustainable and equitable livelihoods," Forests Trees and Livelihoods, vol. 13, no. 3, pp. 203-215, 2003.

[147] B. E. van Wyk, "A broad review of commercially important southern African medicinal plants," Journal of Ethnopharmacology, vol. 119, no. 3, pp. 342-355, 2008.

[148] N. Diederichs, C. Geldenhuys, and D. Mitchell, The First Legal Harvesters of Protected Medicinal Plants in South Africa, 2002, http://www.scienceinafrica.co.za/2002/november/bark.htm.

[149] C. W. Holzapfel, W. Marais, P. L. Wessels, and B. E. Van Wyk, "Furanoterpenoids from Siphonochilus aethiopicus," Phytochemistry, vol. 59, no. 4, pp. 405-407, 2002.

[150] A. M. Viljoen, B. Demirci, K. H. C. Başer, and B. E. Van Wyk, "The essential oil composition of the roots and rhizomes of Siphonochilus aethiopicus," South African Journal of Botany, vol. 68, no. 1, pp. 115-116, 2002.

[151] J. L. S. Taylor, E. E. Elgorashi, A. Maes et al., "Investigating the safety of plants used in South African traditional medicine: testing for genotoxicity in the micronucleus and alkaline comet assays," Environmental and Molecular Mutagenesis, vol. 42, no. 3, pp. 144-154, 2003. 
[152] V. Heywood, "Medicinal and aromatic plants as global resources," Acta Horticulturae (ISHS), vol. 500, pp. 21-30, 1999.

[153] M. Mander, "Marketing of indigenous medicinal plants of South Africa: a case study in Kwazulu-Natal. Food and Agricultural Organization of the United Nations," Food and Agricultural Organization of the United Nations, 1998.

[154] N. R. Crouch, M. C. Lotter, S. Krynauw, and C. PottasBircher, "Siphonochilus aethiopicus (Zingiberaceae), the Prized Indungulu of the Zulu-an overview," Herbertia, vol. 55, pp. 115-129, 2000.

[155] B. E. van Wyk and C. Albrecht, "A review of the taxonomy, ethnobotany, chemistry and pharmacology of Sutherlandia frutescens (Fabaceae)," Journal of Ethnopharmacology, vol. 119, no. 3, pp. 620-629, 2008.

[156] S. Drewes, "Natural products research in South Africa: 1890-2010," South African Journal of Science, vol. 108, no. 5/6, pp. 769-782, 2012.

[157] N. P. Mncwangi and A. M. Viljoen, "Quantitative variation of amino acids in Sutherlandia frutescens (Cancer bush)-towards setting parameters for quality control," South African Journal of Botany, vol. 82, no. 0, pp. 46-52, 2012.

[158] S. Shaik, N. Singh, and A. Nicholas, "HPLC and GC analyses of in vitro-grown leaves of the cancer bush Lessertia (Sutherlandia) frutescens L. reveal higher yields of bioactive compounds," Plant Cell, Tissue and Organ Culture, vol. 105, no. 3, pp. 431-438, 2011.

[159] M. Minocha, N. K. Mandava, D. Kwatra et al., "Effect of short term and chronic administration of Sutherlandia frutescens on pharmacokinetics of nevirapine in rats," International Journal of Pharmaceutics, vol. 413, no. 1-2, pp. 44-50, 2011.

[160] S. E. Shackleton, C. M. Shackleton, T. Cunningham, C. Lombard, C. A. Sullivan, and T. R. Netshiluvhi, "Knowledge on Sclerocarya birrea subsp. caffra with emphasis on its importance as a non-timber forest product in South and southern Africa: a summary. Part 1: Taxonomy, ecology and role in rural livelihoods," Southern African Forestry Journal, no. 194, pp. 27-41, 2002.

[161] A. P. Li, "A comprehensive approach for drug safety assessment," Chemico-Biological Interactions, vol. 150, no. 1, pp. 27-33, 2004.

[162] A. Fugh-Berman, "Herb-drug interactions," The Lancet, vol. 355, no. 9198, pp. 134-138, 2000.

[163] E. Mills, B. C. Foster, R. Van Heeswijk et al., "Impact of African herbal medicines on antiretroviral metabolism," AIDS, vol. 19, no. 1, pp. 95-97, 2005.

[164] N. R. Crouch, E. Douwes, M. M. Wolfson, G. F. Smith, and T. J. Edwards, "South Africa's bioprospecting, access and benefitsharing legislation: current realities, future complications, and a proposed alternative," South African Journal of Science, vol. 104, no. 9-10, pp. 355-366, 2008. 

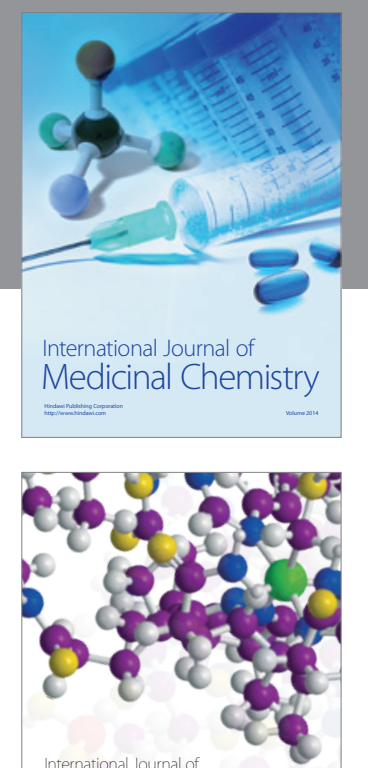

\section{Carbohydrate} Chemistry

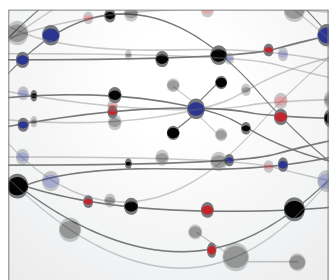

The Scientific World Journal
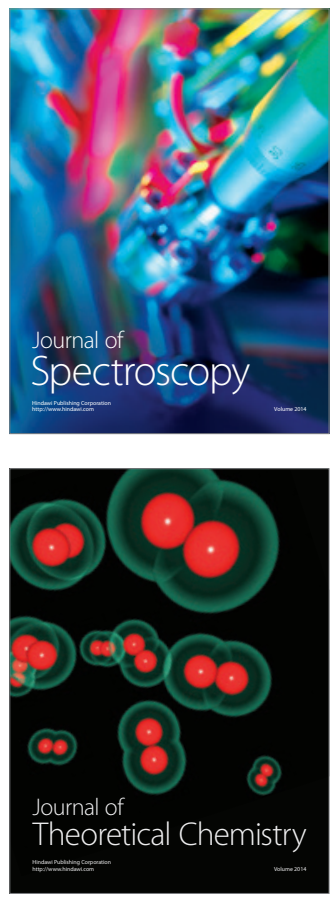
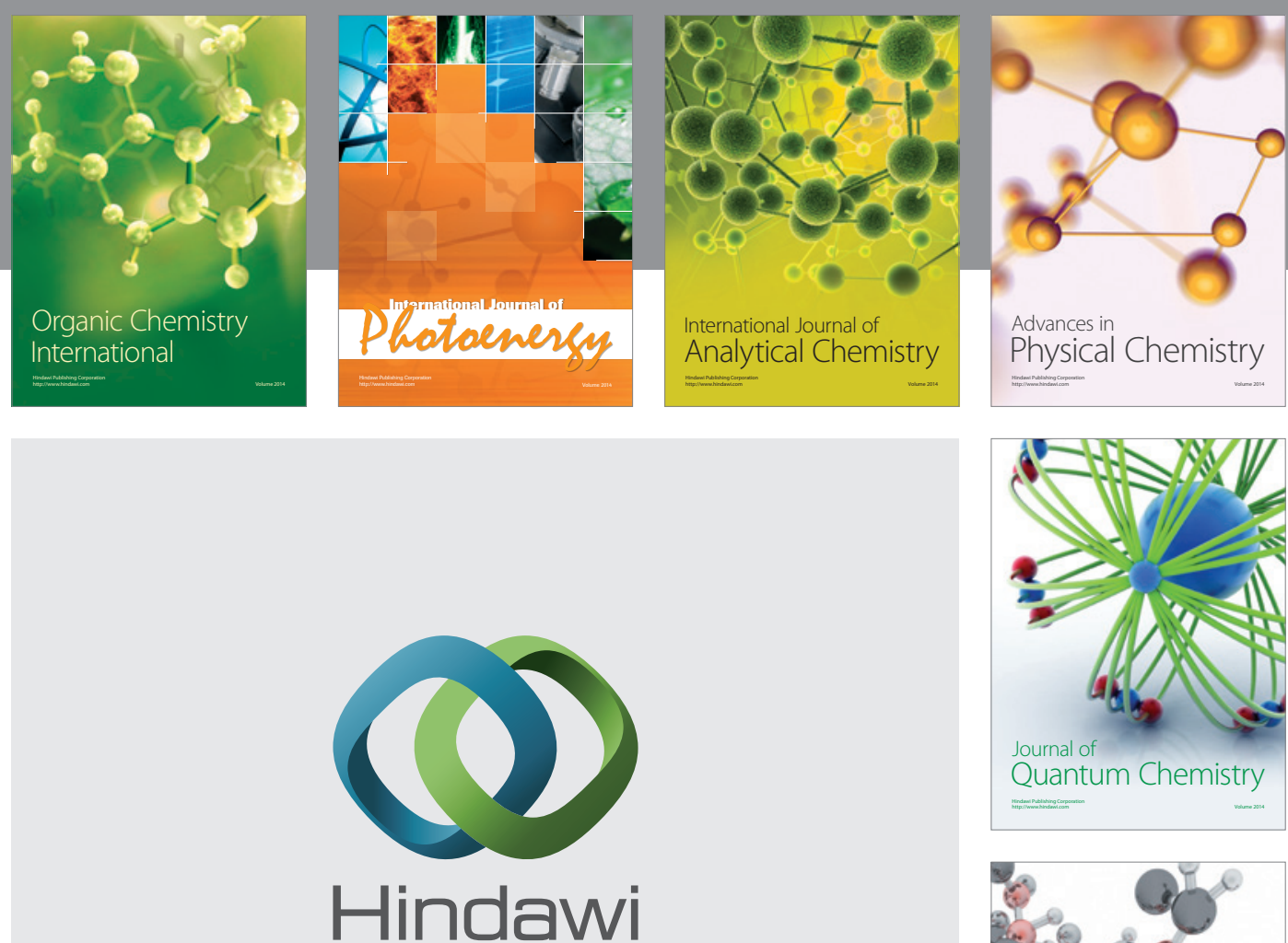

Submit your manuscripts at

http://www.hindawi.com

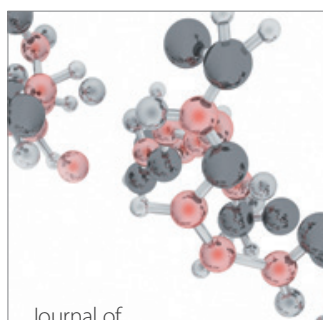

Analytical Methods

in Chemistry

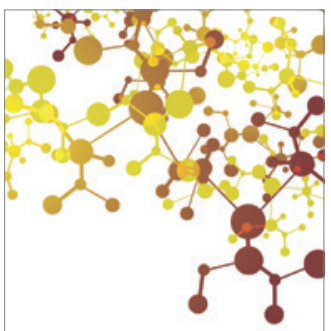

Journal of

Applied Chemistry

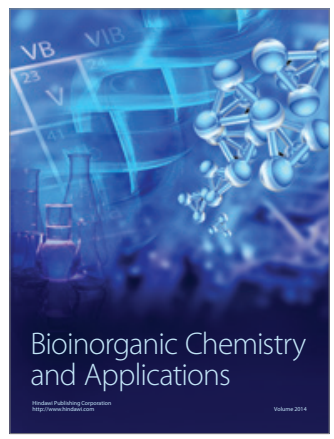

Inorganic Chemistry
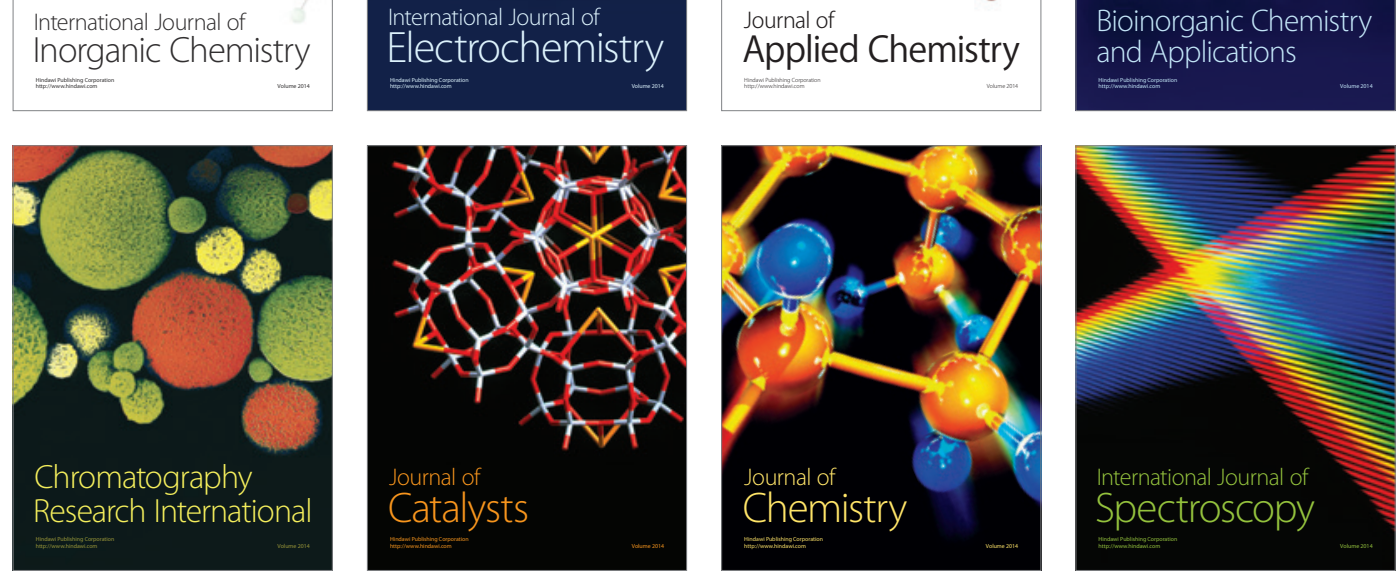